\title{
Fatores que influenciaram os Preços da Ação da Petrobras (PETR4) entre 2009 e
}

\section{0}

\author{
Factors influencing Petrobras Stock Prices (PETR4) between 2009 and 2020 \\ Factores que influyeron en el Precio de las Acciones de Petrobras (PETR4) entre 2009 y 2020
}

\section{Resumo}

Este trabalho objetivou analisar a influência (negativa ou positiva) de variáveis macro e microeconômicas no preço das ações da Petrobras, pelo período de 12 anos, entre o ano de 2009 e o ano de 2020. Os métodos empregados foram: i) correlação de Pearson e; ii) Mínimos Quadrados Ordinários (MQO). Os fatores de natureza qualitativa foram analisados com base numa revisão de literatura. Os principais resultados, obtidos a partir das metodologias empregadas, apontaram que a ação da Petrobras tem o seu preço afetado, principalmente, por fatores como: preço do petróleo Brent, índice Ibovespa e nível de Produção. Estas variáveis foram estatisticamente significantes, no MQO, para explicar as oscilações do preço da ação PETR4. Por fim, vale ressaltar, ademais, que os Indicadores financeiros da empresa, bem como os cenários e as interferências políticas, manifestas, por exemplo, na política de preço dos combustíveis ou em atos de corrupção (que se apresentam como falhas de governança) no âmbito da empresa, podem influenciar, consideravelmente, o comportamento do preço da PETR4.

Palavras-chave: Petrobras; PETR4; Correlação; MQO.

\begin{abstract}
This paper aims to analyze the influence (negative or positive) of macro and microeconomic variables on Petrobras stock price for 12 years, between 2009 and 2020. The methods employed were: i) Pearson's correlation and; ii) Ordinary Least Squares (OLS). The literature review was helpful to understand the qualitative aspects. The main results obtained from both methodologies pointed out that Petrobras' Stock prices were affected by Brent oil price, Ibovespa index, and Production level. These variables were statistically significant in the OLS to explain the fluctuations in the PETR4 share price. Finally, it is worth mentioning that political factors, governance failures (and acts of corruption), Fuel Price Policy, the Political Scenario, and the company's Financial Indicators can also considerably influence the price of PETR4.
\end{abstract}

Keywords: Petrobras; PETR4; Correlation; OLS.

\section{Resumen}

El objetivo de este estudio fue analizar la influencia (negativa o positiva) de variables macro y microeconómicas en el precio de las acciones de Petrobras, para el período de 12 años, entre el año 2009 y el año 2020. Los métodos empleados fueron: i) Correlación de Pearson y; ii) Mínimos cuadrados ordinarios (MCO). Los factores cualitativos se analizaron a partir de una revisión de la literatura. Los principales resultados, obtenidos de las metodologías empleadas, señalaron que el precio de la acción de Petrobras és afectado, principalmente, por factores como: precio del petróleo Brent, índice Ibovespa y el Nivel de producción. Estas variables resultaron estadísticamente significativas, en el MCO, para explicar las fluctuaciones en el precio de la acción PETR4. Finalmente, cabe señalar, además, que los indicadores financieros de la empresa, así como los escenarios e interferencias políticas, se manifiestan, por ejemplo, en la política de precios de los combustibles o en actos de corrupción (que se presentan como fallas de gobernabilidad) en la empresa, pueden influir considerablemente en el comportamiento del precio de PETR4.

Palabras clave: Petrobras; PETR4; Correlación; MCO. 


\section{Introdução}

A globalização financeira está associada aos mercados de capitais em geral, à medida que parte significativa dos fluxos financeiros, associados a cada país, se direcionam para a bolsa de valores, onde são negociadas ações de várias empresas, de setores distintos da economia. Tais organizações buscam captar recursos, no mercado de ações, para financiar a sua produção ou seus projetos de investimento e inovação, por exemplo.

Uma parte significativa das empresas listadas em bolsa guardam relações com o mercado internacional, principalmente as empresas exportadoras e importadoras, pois elas tanto influenciam como são influenciadas pelos níveis de preços dos produtos e pela produtividade das empresas globais dos setores dos quais fazem parte. No Brasil, a Petrobras S/A é um bom exemplo de empresa desta natureza, pois os preços internacionais dos petróleos marcadores (Brent ou WTI) afetam, em alguma medida, os patamares de custos e de preços dos produtos da referida empresa.

A Petrobras é uma empresa do setor de energia, que atua principalmente nos ramos de extração, produção, refino, transporte (abastecimento) e comercialização. Entre os principais produtos por ela produzidos estão o petróleo (e seus derivados) e o gás natural. A Petrobras produz, distribui e comercializa gasolina, diesel e GLP (Gás Liquefeito de Petróleo), por exemplo.

O fato de o principal produto de extração da empresa ser uma commodity (petróleo) ligada a um setor estratégico da economia (o de energia), faz da Petrobras uma empresa atraente para investidores. No entanto, a condição de empresa de economia mista, torna suas ações sensíveis a dois tipos de variações: as de mercado e aquelas oriundas de decisões governamentais. Enquanto os mercados interno e externo influenciam a demanda e a oferta de petróleo (os fundamentos de seu mercado), o governo busca satisfazer as necessidades energéticas nacionais ou até os seus próprios objetivos políticos em suas decisões ou indicações para cargos estratégicos da empresa. Tais circunstâncias podem levar a populismo na política de preços da empresa ou mesmo decisões ineficientes do ponto de vista produtivo ou mercadológico.

Com base nisso, sob uma ótica de análise de mercado, objetiva-se realizar um estudo acerca dos fatores que mais influenciaram as ações preferenciais da Petrobras (PETR4), sejam eles fundamentalistas, macro ou microeconômicos, durante o período de 2009 a 2018. Pretende-se identificar tais variáveis e apresentar reflexões sobre os motivos que os fazem exercer influência sobre o preço da ação PETR4, bem como se eles impactam de forma positiva ou negativa este papel (ação) da Petrobras.

Esse tipo de análise pode ser realizado com empresas de diferentes setores. De acordo com Amorim, Oliveira e Andrade (2020), por exemplo, os principais fatores que influenciaram as empresas do setor sucroenergético do Brasil, de modo geral, foram: i) preço da cana; iii) preço do açúcar; v) IPP_Def (Índice Geral de Preços pagos pela agricultura paulista pelos defensivos agrícolas); vi) dólar; viii) ATR (Açúcar Total Recuperado).

O presente trabalho está estruturado em quatro partes. Esta Introdução contém uma revisão de literatura que aborda especialmente aspectos qualitativos do objeto de estudo. Na segunda seção são apresentados os dois métodos que compõe a Metodologia. Na terceira seção, encontram-se os Resultados e a Discussão. Por fim, a última seção apresenta as Considerações Finais do trabalho.

\subsection{O Mercado de Capitais e a B3}

O mercado de capitais ajuda a melhorar a alocação dos recursos financeiros de um país para atividades econômicas existentes, tais como o comércio e a indústria, proporcionando assim o desenvolvimento socioeconômico, pois os valores mobiliários transacionados neste mercado contribuem para ampliar a liquidez da economia e auxiliam no processo de capitalização das empresas, em geral, e do setor produtivo, em particular.

$\mathrm{O}$ mercado financeiro promove a conexão entre os agentes poupadores e tomadores de recursos (crédito), de modo a suprir parte significativa das necessidades de financiamento dos agentes econômicos que desejam investir e não possuem 
recursos próprios suficientes para isso (Assaf Neto, 2018). Contudo, as economias avançadas (ou com renda per capita mais elevada) costumam apresentar mercados financeiros, em geral, e mercados acionários, em particular, mais desenvolvidos do que aqueles encontrados em economias emergentes. Mercados financeiros mais sofisticados costumam ter graus mais elevados de liquidez, o que favorece os investimentos em longo prazo, na medida em que estimulam os empreendedores a investir.

Segundo Silva (2010), Sant'anna (2008) e Monteiro et al. (2016), o processo de globalização intensificou o fluxo financeiro entre as economias, uma vez que o mercado de capitais permite a atração de recursos externos para os investimentos em companhias de capital aberto, o que ajuda promover o crescimento e potencializar a competitividade das empresas, em especial, e do país, em geral.

As ações representam uma parcela de todo o capital da empresa que emitiu os títulos. Os detentores destes títulos são sócios da empresa por terem adquiro seus papéis. Os preços dessas ações variam conforme o desempenho passado e atual da empresa, assim como em função das expectativas dos investidores quanto ao futuro da companhia, ou seja, são afetadas pelas perspectivas de crescimento do país e da expansão das empresas de sua lucratividade. De um outro ângulo, Fortuna (2020) resume que o preço das ações deriva das relações de oferta e demanda que refletem as condições econômicas tanto do país quanto da empresa.

Para Sant'anna (2008), os indicadores financeiros podem apontar uma perspectiva positiva ou negativa a respeito de uma determinada empresa. Os investidores utilizam tais informações para a tomada de decisão quanto a investir ou não em determinada empresa. Desse modo, ao adquirir ações de uma empresa, o agente superavitário acredita no potencial de lucro ou crescimento da organização ou de valorização da ação adquirida.

No Brasil, em 1968, foi criado o Índice Bovespa, que expressa o desempenho médio de uma carteira teórica representativa das principais empresas negociadas na B3. Este índice é comumente utilizado como "termômetro" do mercado acionário brasileiro, sinalizando também as interpretações e expectativas quanto o desempenho da economia do País. De acordo com Silva et al (2005), o Ibovespa é um valor responsável por expressar o desempenho de uma carteira hipotética de ações, para que os agentes entendam o comportamento do mercado, em determinados períodos.

Para Assaf Neto (2018), o referido índice deve conter ações que sejam sensíveis às possíveis oscilações do mercado, permitindo a existência de estudos sobre os diversos temas correlatos ao mercado acionário. É relevante ressaltar ainda, que as ações das empresas com grande representatividade no Ibovespa, naturalmente, se refletem, consideravelmente, nas variações do índice.

Não raro, eventos macroeconômicos internacionais afetam o Ibovespa. A globalização e a internacionalização do capital elevaram o grau de integração dos mercados. Logo, na medida em que os mercados estão mais interconectados a correlação entre seus movimentos também se eleva. Segundo Nunes Maranhão e Oliveira (2017), "há transbordamentos de choques cambiais e de mercados financeiros para o índice Ibovespa, sendo que essas correlações apresentam dinâmica temporal, com transbordamentos sempre na direção dos choques para o índice Ibovespa”.

Bernardo, Albanez e Securato (2018) apontam que são escassos na literatura trabalhos que discutem a influência dos fatores macroeconômicos e institucionais nas empresas. Os autores analisam como tais aspectos afetam a estrutura de capital das empresas, embora as variáveis intrínsecas às próprias empresas podem afetar ainda mais os seus resultados, caso, no objeto de análise, predominem empresas eminentemente privadas, de capital aberto.

\subsection{Desafios e Avanços Recentes da Petrobras}

Segundo Costa (2016), a criação da Petrobras tinha como finalidade a construção de novas refinarias e aumentar a oferta de produtos derivados de petróleo, a empresa em questão, viria a cumprir um papel importante na complementação e 
universalização do abastecimento do mercado interno e, consequentemente, diminuir a dependência brasileira por petróleo estrangeiro e mitigar os efeitos dos choques de petróleo (1973 e 1979). Com esses propósitos, a empresa se dedicaria a encontrar novas jazidas de petróleo e de gás natural no território brasileiro, contribuindo para atingir o objetivo de promoção da autossuficiência energética.

Cada sucesso obtido nos programas de desenvolvimento tecnológico da Petrobras impulsionavam a empresa a investir cada vez mais em pesquisa e tecnologia. Conforme Petrobras (2021), graças a esses esforços, que em meados de 2006, foi encontrada os primeiros indícios de petróleo na camada Pré-sal, na costa brasileira, dando início às atividades de extração a partir de 2008. Com isso a empresa passou a ter novos horizontes na indústria de petróleo mundial, na medida em que passou a realizar uma "exploração em um alto nível.

Diante do potencial lucrativo da descoberta de grandes reservas na camada Pré-sal, atraiu-se o interesse de muitos investidores nacionais e internacionais, o que levou a empresa a impulsionar ainda mais o ritmo de expansão dos seus investimentos e da sua produção. Contudo, essa situação também chamou a atenção de empresários e de agentes políticos que se envolveram a práticas de corrupção e lesaram a Petrobras (e seus acionistas), em particular, e o patrimônio público, em geral, por se tratar de uma empresa estatal (de economia mista). De acordo com Almeida et al (2017) e Faria et al (2015), a Petrobras é atualmente uma das principais empresas brasileiras e maior estatal do setor petrolífero da América Latina. No entanto, desde 2014, as práticas ilícitas envolvendo contratos realizados pela empresa vinham sendo investigadas pelo Ministério Público Federal (MPF), e Polícia Federal (PF), com o fito de identificar as irregularidades envolvendo empreiteiras e fornecedores da empresa, no âmbito da operação denominada Lava Jato.

A operação Lava Jato gerou impactos notáveis na empresa, uma vez que lançou suspeitas sobre a gestão da empresa a obrigou a fazer um acordo de cerca de 10 bilhões de reais, com o regulador do mercado financeiro dos Estados Unidos, em indenizações aos investidores daquele mercado. De acordo com Martins et al. (2015), o mais importante está associado aos investidores, na medida em que a credibilidade da companhia passou a ser contestada pelo mercado financeiro, naquele contexto. Parte significativa dos agentes reduziu os seus investimentos na empresa, o que diminuiu a atratividade e o preço dessas ações nos anos seguintes à deflagração da operação Lava Jato. A redução da demanda dessas ações foi um dos fatores determinantes para a redução do valor de mercado da companhia.

Entre 2014 e 2015, Faria et al (2015) identificou que a situação supramencionada gerou um impacto considerável nas ações da empresa, as quais se desvalorizaram em momentos que coincidem com notícias oriundas das operações da Lava Jato, associadas à atos de corrupção envolvendo contratos firmados pela Petrobras. O autor lembrou o balanço patrimonial que foi corrigido em 2015, o qual apontava perdas da empresa no terceiro semestre de 2014, também resultou em queda do preço das ações. Por fim, Almeida et al (2017) apontou que o reconhecimento dos atos de corrupção foi o principal determinante da queda no lucro líquido da empresa.

De acordo com Padula e Albuquerque (2018), muitos dos casos de corrupção do Brasil provocaram uma significativa desvalorização nas maiores empresas estatais transacionadas na B3 e também de suas American Depositary Receipt (ADR), que são negociadas no exterior e guardam correspondência com ações negociadas no mercado à vista brasileiro. Isso promoveu uma fuga de recursos financeiros destas empresas e contribuiu para uma queda no crescimento econômico, o que corrobora a teoria que aponta que a corrupção gera prejuízo em longo prazo. As ações da Petrobras negociadas no exterior foram mais sensíveis a esses eventos de corrupção do que aquelas negociadas na bolsa de valores nacional.

Shimabuku (2017) analisou o efeito da corrupção nos preços das ações da Petrobras entre o período de 2011 e 2016. O autor constatou que as operações fraudulentas eram práticas relativamente antigas e que os procedimentos antifraudes não eram efetivos antes da operação Lava Jato, a partir da qual a empresa reduziu o seu patrimônio, os seus investimentos em Sustentabilidade, tanto na área social quanto ambiental. O autor conclui que a principal motivação para a queda do valor de 
mercado (preço das ações) da Petrobras foi as falhas na detecção de fraudes, tanto pelos Controles Internos quanto pelas Auditorias Externas contratadas pela Petrobras, que não encontraram problemas antes das descobertas realizadas pós-Lava-Jato.

Segundo Juaçaba (2018), a Petrobras e a norueguesa Statoil (atual Equinor) há muito tempo são consideradas modelos para outras petroleiras estatais, nos seguintes aspectos: práticas de gestão, transparência, eficiência e criação de valor. No entanto, ambas as empresas experimentaram corrupção nas últimas décadas. $\mathrm{O}$ autor concluiu que a cultura nacional cumpre um papel contextual importante na causa da corrupção, por um lado, e no grau de eficiência das instituições voltadas para a sua prevenção e detecção, assim como a composição do conselho de administração das empresas pode desempenhar um papel-chave ao criar mais óbices para as práticas de corrupção.

Diante disso, Juaçaba (2018) apontou que os níveis contrastantes de corrupção na Petrobras e na Statoil podem ser atribuídos à captura política da Petrobras, manifesta, também, no conselho de administração. Contudo, qualquer tentativa de solucionar o problema poderia ter a sua eficácia limitada por uma estrutura de corrupção sistêmica profundamente enraizada em traços culturais, como seria notado no Brasil.

Segundo Jesus Júnior, Sarti, Ferreira Jr (2016), a deterioração da situação econômico-financeira da Petrobras conduziu ao rebaixamento métricas de crédito pelas agências de rating, até o ano de 2015. As circunstâncias que favoreceram essa situação foram, por exemplo: i) ambicioso programa de investimentos da companhia e; ii) significativa exposição à interferência política; iii) represamento de preços dos derivados (combustíveis), mantidos abaixo da paridade internacional; iv) elevadas metas de conteúdo local; v) queda nos indicadores de rentabilidade. Esses fatores elevaram custos e reduziram os preços médios de venda enfrentados pela Petrobras, de modo a comprometer os seus resultados econômico-financeiros.

Ainda assim, sete anos após o descobrimento do Pré-sal (em 2013), a companhia chegou a produzir cerca de 300 mil barris de petróleo por dia. Em 2016 a empresa atingiu a marca de 1 milhão de barris de petróleo por dia, na camada do Pré-sal. Este resultado foi alcançado em menos de 10 anos depois da descoberta das jazidas, o que comprovou a viabilidade técnica, econômica e operacional do Pré-sal, bem como as competências produtivas e gerenciais da Petrobras, na medida em que a empresa promoveu inovações importantes e escalou a produção naquele ambiente operacional com elevada produtividade e economicidade. No ano de 2020, a produção de óleo e gás foi de 2,8 milhões de barris de petróleo equivalente por dia (boed). Destes, 1,5 milhões de boed foram extraídos do Pré-sal (Petrobras, 2021).

\subsection{Objeto de Pesquisa}

O presente trabalho parte da seguinte pergunta: "quais variáveis macro e microeconômicas influenciaram o desempenho da ação PETR4 e como isso ocorre?”. A delimitação temporal do objeto de pesquisa envolve o período que vai de 2009 a 2020, o qual tem início em um período de Pós-crise (Crise Financeira dos EUA, associada ao subprime). Neste contexto, a pergunta pode ser reescrita da seguinte maneira: "quais variáveis macro e microeconômicas influenciaram o desempenho da ação PETR4 e como isso ocorreu no período de 2009 a 2020?".

A escolha do objeto de pesquisa (ação da Petrobras) para a realização deste estudo se justifica por alguns pontos importantes. Primeiro, Almeida et al (2017) aponta que a Petrobras tem grande influência na vida dos brasileiros, por ser a empresa que abastece o País em praticamente sua totalidade, bem como pelo fato de ela ser uma das principais estatais do Brasil. Ademais, a Petrobras é a maior companhia do setor de energia do Brasil, uma das petroleiras mais importantes do mundo, bem como, nos últimos anos, foi a empresa, no Brasil, com maior volume diário de negociação e um dos mais elevados valores de mercado de organizações listadas na B3.

Segundo Kahil (2018) a Economatica elaborou um levantamento em 2018 com as ações mais negociadas na bolsa brasileira de 2014 a 2018. Este levantamento apontou que a Petrobras lidera este indicador em todos os anos, sendo a empresa 
com maior volume de negociações da bolsa brasileira. O volume financeiro médio das ações da empresa Petrobras, no ano de 2018, foi de R\$ 1,4 Bilhões de reais por dia, seguido da Vale (R\$ 882,6 Milhões/dia), ItauUnibanco (R\$ 644,7 Milhões/dia), e Bradesco (R\$ 451,8 Milhões/dia).

Azevedo e Ryngelblum (2019) apresentam na revista Valor Econômico os dados referentes ao valor de mercado das empresas listadas na B3, no início do ano de 2019, a qual apresenta o ItauUnibanco como empresa de maior valor de mercado na B3 com cerca de R \$ 342,1 Bilhões, seguido pela Petrobras (R\$ 340,5 Bilhões), Bradesco (R \$ 259,6 Bilhões) e Vale (R \$ 259,0 Bilhões). O valor de mercado é calculado pela multiplicação do número de ações da empresa pelo valor da ação desta mesma empresa em determinado dia.

A Figura 1 apresenta as quatro empresas com maior valor de mercado e as mais negociadas, em 2021. Tratam-se das mesmas organizações, que são as quatro maiores empresas do mercado de ações brasileiro.

Figura 1 - Empresas com maior valor de mercado e mais negociadas (na B3) no Brasil em 2021.

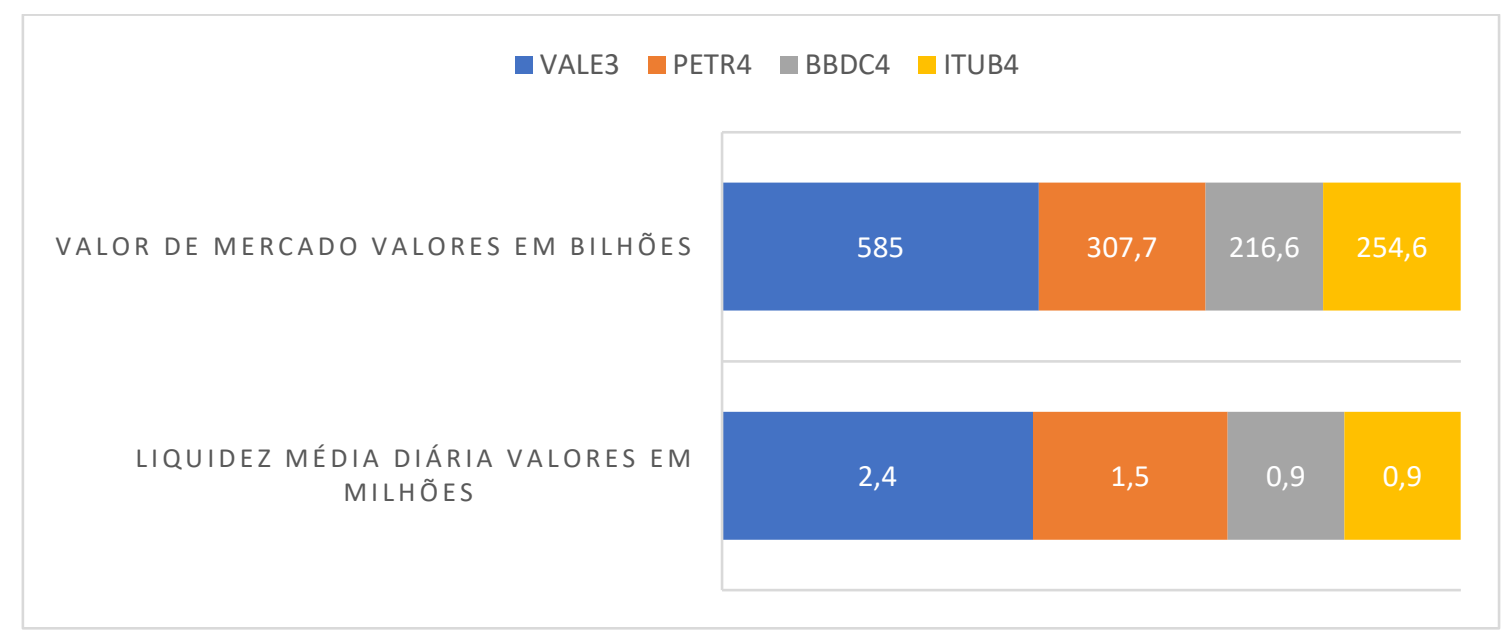

Fonte: Elaborado pelos Autores, adaptado de Status Invest (2021).

O sucesso dos negócios de uma empresa depende de muitos fatores, entre eles se destacam as condições macroeconômicas e os fatores relacionados à gestão da empresa (SANT’ANNA, 2008. pg.11).

Na próxima seção será apresentada a metodologia empregada neste artigo, que contempla um método estatístico e outro econométrico.

\section{Metodologia}

Neste sentido, para auxiliar no estudo, além de buscar uma referência teórica básica, foram coletados dados da série histórica de preços das ações preferenciais da Petrobras (PETR4) para confrontá-las com outras bases de dados históricos, quais sejam: Ibovespa, Taxa Selic, Dólar, Risco País, Preço Doméstico dos Combustíveis (Gasolina e Diesel) e o valor internacional do barril de petróleo, o Brent. Para todos os dados citados acima o período temporal será o mesmo, qual seja: de 2009 a 2020. As séries de preços foram deflacionas, utilizando o Índice de Preços ao Consumidor Amplo (IPCA).

\subsection{Modelo Estatístico}

O presente trabalho se caracteriza como pesquisa quali-quantitativa, uma vez que se vale de dados secundários para a aplicação de um método estatístico (Correlação de Pearson) e de técnicas econométricas para a obtenção de resultados quantitativos, fundamentadas e complementadas por análises qualitativas, que ajudam a compreender fenômenos não 
quantificáveis ou não puramente econômicos, como por exemplo: conflitos internacionais, fatos políticos e corrupção. Este trabalho, portanto, buscou identificar fatores que influenciaram os preços da ação da Petrobras, sejam eles aspectos quantitativos ou qualitativos.

O método de correlação de Pearson, segundo Lira (2004), permite o estudo das relações ou associações de variáveis, usualmente utilizado para mostrar o grau de relacionamento (como uma muda quando a outra se altera) entre elas. O cálculo utilizado para a identificação da matriz de correlação é representado pela formula a seguir:

$$
r=\frac{n\left(\sum x y\right)-\left(\sum x\right)\left(\sum y\right)}{\sqrt{n\left(\sum x^{2}\right)-\left(\sum x\right)^{2}} * \sqrt{n\left(\sum y^{2}\right)-\left(\sum y\right)^{2}}}
$$

Conforme Callegari-Jacques (2003, apud LIRA, 2004, p. 54), a interpretação do resultado de uma correlação depende do objetivo de sua utilização. No entanto o coeficiente de correlação linear é um número puro que varia de -1 a +1 , sua interpretação dependerá do valor número e o sinal que o acompanha. A tabela 1 apresenta a interpretação do resultado.

Tabela 1 - Interpretação do valor de $r$.

\begin{tabular}{c|l}
\hline Valor de $\rho$ & \multicolumn{1}{c}{ Interpretação } \\
\hline$-1,00$ a $-0,90$ & Correlação negativa muito forte \\
\hline$-0,89$ a $-0,70$ & Correlação negativa forte \\
\hline$-0,69$ a $-0,40$ & Correlação negativa moderada \\
\hline$-0,39$ a $-0,20$ & Correlação negativa fraca \\
\hline$-0,19$ a 0,00 & Correlação negativa muito fraca \\
\hline 0,00 & Correlação Nula \\
\hline 0,00 a 0,19 & Correlação positiva muito fraca \\
\hline 0,20 a 0,39 & Correlação positiva fraca \\
\hline 0,40 a 0,69 & Correlação positiva moderada \\
\hline 0,70 a 0,89 & Correlação positiva forte \\
\hline 0,90 a 1,00 & Correlação positiva muito forte \\
\hline \multicolumn{2}{c}{ Fonte: Elaborado pelos autores (2019). }
\end{tabular}

Na seção seguinte será apresentado o modelo econométrico proposto por este trabalho.

\subsection{Modelo Econométrico}

O objetivo desta parte do artigo é apresentar as características do modelo que servirá de base para a análise econométrica dos determinantes do preço da ação PETR4 (ação preferencial da empresa Petróleo Brasileiro S.A). Para este propósito, utilizouse séries de tempo com 2.626 observações diárias, entre 02 de janeiro de 2009 a 30 de dezembro de 2019. Para avaliar o comportamento da PETR4, utilizou-se como variáveis explicativas a cotação diária do barril do Petróleo (US\$) no mercado internacional do tipo Brent (Brent), a cotação cambial ao fim do dia para a compra (cam), o índice da bolsa de valores de São Paulo (Ibov), a produção diária de Petróleo pela Petrobrás (Prod), o risco país $(R P)$ e a taxa SELIC (R). As séries estatísticas foram obtidas junto ao banco de dados disponível no site www.investing.com, a exceção da série temporal da taxa Selic e para 
o risco país que foram obtidas junto ao banco de dados do Instituto de Pesquisa Econômica Aplicada (IPEADATA). A função estimada apresenta a seguinte forma:

(2) Petr $4=f($ brent, cam, ibov, prod, $R P, r)$

As séries utilizadas na estimação são séries temporais ordenadas no tempo. Os métodos usuais de estimação - Mínimos Quadrados Ordinários (MQO) - pressupõem que essas séries temporais são estacionárias (média e variância constante), e só assim podem apresentar estimadores consistentes. A estacionariedade de um processo estocástico é devido à ausência de raiz unitária ou de tendência estocástica no processo autorregressivo que gera as séries de tempo. São os testes de raiz unitária que verificam a presença (ou ausência) de raiz unitária nas variáveis utilizadas nas estimações e, consequentemente, conduzem o estudo para uma determinada metodologia. Logo, o primeiro passo de uma análise econométrica é verificar se as séries temporais são estacionárias em nível.

Utilizando o pacote econométrico E-views 10, foram realizados os testes de raiz unitária Augmented Dickey-Fuller (ADF), Phillips-Perron (PP) e Kwiatkowski-Phillips-Schmidt-Shin (KPSS) das séries de tempo em análise neste estudo. O número de defasagens foi definido a partir da minimização do critério de Schwartz. O valor crítico para estabelecer a existência ou não de raiz unitária foram tabuladas por MacKinnon (1996). Utilizou-se um valor crítico de 5\% como referência para a determinação da existência (ou não) de raiz unitária. A escolha do nível de integração das variáveis considera a significância estatística do intercepto e da tendência. A tabela 2 apresenta os testes de raiz unitária. Os testes ADF e PP assumem a hipótese nula de que a série apresenta uma raiz unitária. O teste KPSS considera a hipótese nula de que a série é estacionária. Na próxima seção deste artigo serão discutidos os resultados do trabalho.

\section{Resultados e Discussão}

\subsection{Resultados do Modelo Econométrico}

A Tabela 2 apresenta a análise da raiz unitária, mostrando que todas as séries temporais utilizadas neste estudo são integradas de ordem um, I(1), ou seja, precisam ser diferencias uma vez para tornarem-se estacionárias em nível. A exceção é a série temporal da taxa SELIC, I(0). Tomando a primeira diferença das séries temporais I (1) , a metodologia usual dos Mínimos Quadrados Ordinários (MQO) é condizente para apresentar resultados consistentes. 
Research, Society and Development, v. 10, n. 7, e13410716294, 2021

(CC BY 4.0) | ISSN 2525-3409 | DOI: http://dx.doi.org/10.33448/rsd-v10i7.16294

Tabela 2 - Teste de Raiz Unitária ADF, PP e KPSS.

\begin{tabular}{|c|c|c|c|c|c|c|c|}
\hline $\begin{array}{c}\text { Teste/ } \\
\text { Variável }\end{array}$ & ADF & $\mathbf{I}(\mathbf{p})$ & $\mathbf{P P}$ & $\mathbf{I}(\mathbf{p})$ & KPSS & $\mathbf{I}(\mathbf{p})$ & $\begin{array}{c}\text { Ordem de } \\
\text { Integração }\end{array}$ \\
\hline \multirow{2}{*}{ BRENT } & $-51,7616 c^{*}$ & \multirow{2}{*}{ I (1) } & $-57,7584 c^{*}$ & \multirow{2}{*}{ I (1) } & $0,7461 a^{*}$ & \multirow{2}{*}{ I (1) } & \multirow{2}{*}{ I (1) } \\
\hline & {$[-2,5658]$} & & {$[-2,5658]$} & & {$[0,2160]$} & & \\
\hline \multirow{2}{*}{ CAM } & $-40,2509 c^{*}$ & \multirow{2}{*}{ I (1) } & $-56,0702 c^{*}$ & \multirow{2}{*}{ I (1) } & $0,4805 a^{*}$ & \multirow{2}{*}{ I (1) } & \multirow{2}{*}{ I (1) } \\
\hline & {$[-2,5658]$} & & {$[-2,5658]$} & & {$[0,2160]$} & & \\
\hline \multirow{2}{*}{ IBOV } & $-52,2368 b^{*}$ & \multirow{2}{*}{ I (1) } & $-52,3517 b^{*}$ & \multirow{2}{*}{ I (1) } & $1,1737 \mathrm{a}^{*}$ & \multirow{2}{*}{ I (1) } & \multirow{2}{*}{ I (1) } \\
\hline & {$[3,4327]$} & & {$[-3,4327]$} & & {$[0,2160]$} & & \\
\hline \multirow{2}{*}{ PETR4 } & $-52,0138 c^{*}$ & \multirow{2}{*}{ I (1) } & $-52,0077 \mathrm{c}^{*}$ & \multirow{2}{*}{ I (1) } & $1,1337 a^{*}$ & \multirow{2}{*}{ I (1) } & \multirow{2}{*}{ I (1) } \\
\hline & {$[-2,5658]$} & & {$[-2,5658]$} & & {$[0,2160]$} & & \\
\hline \multirow{2}{*}{ PROD } & $-51,2152 c^{*}$ & \multirow{2}{*}{ I (1) } & $-51,2152 c^{*}$ & \multirow{2}{*}{ I (1) } & $0,4614 a^{*}$ & \multirow{2}{*}{ I (1) } & \multirow{2}{*}{ I (1) } \\
\hline & {$[-25658]$} & & {$[-2,5658]$} & & {$[0.2160]$} & & \\
\hline \multirow{3}{*}{$\mathrm{R}$} & $-2,0414 c^{* * *}$ & \multirow{3}{*}{$\mathrm{I}(0)$} & $-2,0173 c^{* *}$ & \multirow{3}{*}{ I (0) } & $0,7681 a^{*}$ & \multirow{3}{*}{ I (1) } & \multirow{3}{*}{$\mathrm{I}(0)$} \\
\hline & & & & & & & \\
\hline & {$[-1,9409]$} & & {$[-1,9409]$} & & {$[0,2160]$} & & \\
\hline \multirow{3}{*}{$\mathrm{RP}$} & $-50,0945 c^{*}$ & \multirow{3}{*}{ I (1) } & $-50,4871 c^{*}$ & \multirow{3}{*}{ I (1) } & $0,4836 a^{*}$ & \multirow{3}{*}{ I (1) } & \multirow{3}{*}{ I (1) } \\
\hline & & & & & & & \\
\hline & {$[-2,5658]$} & & {$[-2,5658]$} & & {$[0,2160]$} & & \\
\hline
\end{tabular}

Nota: ADF e PP utilizam a estatística $\tau$ e KPSS utiliza a estatística LM. A rejeição da hipótese nula a $1 \%$ e $5 \%$ é indicada por * e **, respectivamente e os valores críticos das estatísticas indicados em [ ]. Os diagnósticos sobre ordem de integração são indicados por I (0) para variáveis estacionárias em nível e I (1) para variáveis integradas de ordem 1 e não-estacionárias em nível. A presença de constante e tendência é indicada pela notação 'a'. A notação 'b' indica a presença de constante e 'c' indica a ausência de constante e de tendência. Fonte: Elaborada pelos autores com o uso do pacote econométrico E-views 10.

Assim sendo, para analisar o comportamento da ação PETR4, utilizou-se a seguinte função:

(3) PETR4 $=c+\beta_{1}$ Brent $+\beta_{2}$ Cam $+\beta_{3}$ Ibov $+\beta_{4}$ Prod $+\beta_{5} R P+\beta_{6} R+\varepsilon_{t}$

A Tabela 3 apresenta os resultados da estimação por MQO. Onde c é o intercepto da reta estimada, os $\beta s$ são os coeficientes de inclinação da reta estimada e $\varepsilon$ o termo de erro. 
Research, Society and Development, v. 10, n. 7, e13410716294, 2021

(CC BY 4.0) | ISSN 2525-3409 | DOI: http://dx.doi.org/10.33448/rsd-v10i7.16294

Tabela 3 - Coeficientes estimados da equação por MQO.

\begin{tabular}{|c|c|c|c|}
\hline Variável & Coeficiente Estimado & Estatística $\mathbf{t}$ & $\begin{array}{c}\text { Probabilidade de aceitar a } \\
\text { hipótese nula }\end{array}$ \\
\hline Constante (c) & 0,05887 & 1,0701 & 0,2847 \\
\hline Brent & 0,02871 & 7,0687 & $0,0000^{\mathrm{a}}$ \\
\hline Cam & $-0,232292$ & $-1,0603$ & 0,2891 \\
\hline Ibov & 0,000363 & 49,3827 & $0,0000^{\mathrm{a}}$ \\
\hline Prod & $-0,018976$ & $-1,9069$ & $0,0566^{\mathrm{b}}$ \\
\hline $\mathrm{RP}$ & $2,87 \mathrm{E}-05$ & 0,0325 & 0,9741 \\
\hline $\mathrm{R}$ & $-0,39331$ & $-0,1306$ & 0,8961 \\
\hline$\overline{\mathrm{R}^{2}}$ & \multicolumn{2}{|c|}{0,6014} & - \\
\hline Estatísitca F & \multicolumn{2}{|c|}{658,5065} & 0,0000 \\
\hline $\begin{array}{c}\text { Estatística } \\
\text { Durbin-Watson }\end{array}$ & \multicolumn{2}{|c|}{1,9745} & - \\
\hline
\end{tabular}

Nota: $a$ indica que os parâmetros estimados são significativamente diferentes de zero ao nível de 1, 5 e $10 \%$.

$b$ indica que os parâmetros são significativamente diferentes de zero ao nível de 10\%. Fonte: Resultados gerados pelo E-Views 10 (2021).

De acordo com a tabela 3, apenas as variáveis Brent, Ibov e Prod foram estatisticamente significantes para explicar as oscilações da PETR4. As demais variáveis, ao nível de significância de 5\% ou 10\%, embora sejam necessárias dentro do modelo (variáveis de controle) não se mostraram estatisticamente significantes.

Os resultados mostram que tanto o índice Ibovespa assim como o valor do preço do barril do petróleo Brent, no mercado internacional, possuem correlação positiva com o preço das açães da Petrobras (Petr4). Quando o Ibov sobe 1\%, a cotação da PETR4 aumenta em R \$ 0,0003 e quando o preço do barril do petróleo se eleva em US\$1, o preço da ação PETR4 sobe R $\$ 0,028$. Por sua vez, quando a produção aumenta em $1 \%$, o preço da ação PETR4 cai R \$ 0,018. Por fim, a regressão aqui estimada explica as variações da ação PETR4 em 60,13\%, ficando o restante (39,87\%) a cargo do termo de erro.

A investigação empírica com o uso de amostras grandes exige a observância da estabilidade do modelo estimado. Isso pode ser obtido através do teste de estabilidade de Chow. A figura 2 apresenta o resutlado deste teste: 
Research, Society and Development, v. 10, n. 7, e13410716294, 2021

(CC BY 4.0) | ISSN 2525-3409 | DOI: http://dx.doi.org/10.33448/rsd-v10i7.16294

Figura 2 - Resultado do teste de estabilidade de Chow.

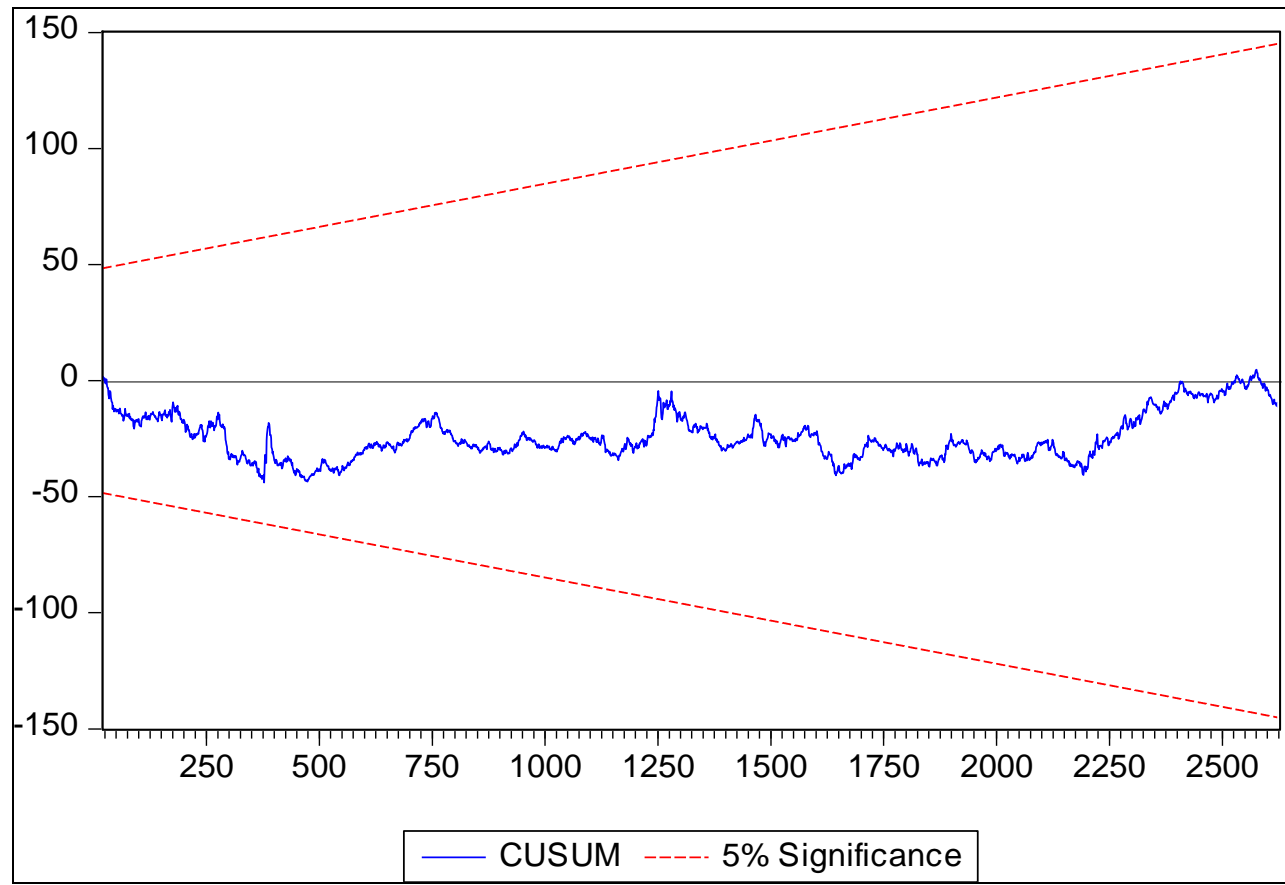

Fonte: Resultados gerados pelo E-Views 10 (2021)

Observa-se, a partir da figura 2, que a estimação com 2626 observaçoes foi corretamente especificada. Como o resultado obtido pelo teste apresenta um índice que permanece dentro do nível de sinigificância de 5\%, pode-se afirmar que os coeficientes estimados na análise são estáveis.

Na metodologia dos Mínimos Quadrados Ordinários (MQO), faz-se necessário que o termo de erro assuma um comportamento determinado para que os estimadores sejam do tipo BLUE, ou seja, se estime os melhores estimadores lineares não viesados, a saber: 1) o valor médio do erro aleatório tem que ser ZERO: $E(e)=0 ; 2)$ a variância do erro tem que ser constante ao longo da reta estimada: $\left.\operatorname{var}(e)=\sigma^{2} ; 3\right)$ os termos de erros encontrados não podem ser correlacionados: $\left.\operatorname{cov}\left(e_{i}, e_{j}\right)=0 ; 4\right)$ a variável $x$ não é aleatória e deve conter, pelo menos, dois valores diferentes; 5) os valores do termo de erro (e) se distribuem normalmente em torno da sua média. Os resultados da estatística descritiva para o termo de erro são apresentados na tabela 4 : 
Research, Society and Development, v. 10, n. 7, e13410716294, 2021

(CC BY 4.0) | ISSN 2525-3409 | DOI: http://dx.doi.org/10.33448/rsd-v10i7.16294

Tabela 4 - Estatística descritiva do termo de erro estimado na regressão MQO.

\begin{tabular}{c|c} 
Média & $1,15 \mathrm{E}-18$ \\
Mediana & 0,0047 \\
Valor Máximo Observado & 2,8400 \\
Valor Mínimo Observado & $-1,2287$ \\
Desvio Padrão & 0,2811 \\
Kurtosis & 12,2101 \\
Teste Jarque-Bera & Probabilidade $=0,0000$ \\
Número de observações & 2626 \\
\hline
\end{tabular}

Fonte: Resultados gerados pelo E-Views 10 (2021).

Pelos resultados obtidos, é possível observar que o termo de erro tem média zero. É necessário que haja pelo menos dois termos com valores distintos. De acordo com os resultados, há 2626 observações. Destas, a que apresenta o valor máximo é distinta da que apresenta o valor mínimo. Além disso, para testar a normalidade da distribuição do erro utiliza-se o teste JarqueBera. O resultado deste teste mostra que a probabilidade de se rejeitar a hipótese nula (normalidade) é de $0 \%$.

Para se testar a autocorrelação serial, utiliza-se o teste Durbin Watson. De acordo com valores críticos obtidos junto a tabela de Durbin Watson para uma regressão com 2626 observações e uma variável explicativa, entre 1,810 a 2,19 não existe evidências de autocorrelação. Como o resultado do teste Durbin-Watson (tabela 3) foi 1,9745, aceita-se a hipótese nula de que as observações são não autocorrelacionadas.

Por fim, para testar se a variância do erro é homocedástica, ou seja, se a variância é constante, utilizou-se o teste ARCH de heterocedasticiade, cuja estatística-F corresponde a 48,9353 e a probabilidade de rejeitar a hipótese nula é de 0,0000. O resultado deste teste é apresentado na tabela 5:

Tabela 5 - Teste de heterocedasticiade de ARCH do termo de erro.

\begin{tabular}{lcc}
\hline Estatística & Resultado & Probabilidade de rejeitar a hipótese nula \\
\hline Estatística F & 48,9353 & 0,0000 \\
\hline
\end{tabular}

Fonte: Resultados gerados pelo E-Views 10 (2021).

De acordo com o teste de heterocedasticidades, observa-se que a probabilidade de se rejetar a hipótese nula (homocedasticidade) é de 0\%; ou seja, em 100\% das vezes, as observações do termo de erro são homocedasticas. Sendo assim, com base nos testes sobre o resíduo, pode-se assumir que foram estimados os melhores estimadores não viesados.

\subsection{Resultados do Modelo Econométrico}

O quadro 1 apresenta os principais acontecimentos de cada respectivo ano. $\mathrm{O}$ seu objetivo é sintetizar os pontos chave, que tenham exercido influência nos resultados da Petrobras e no preço da sua ação. O quadro está segmentado em fatores internos e fatores externos. O intuito é distinguir os fatores macroeconômicos dos microeconômicos, destacando aqueles que foram mais decisivos no comportamento das ações da empresa. 
Research, Society and Development, v. 10, n. 7, e13410716294, 2021

(CC BY 4.0) | ISSN 2525-3409 | DOI: http://dx.doi.org/10.33448/rsd-v10i7.16294

Quadro 1 - Fatores internos e externos de maior relevância para a Petrobras.

\begin{tabular}{|c|c|c|}
\hline & Fatores internos & Fatores externos \\
\hline 2009 & $\begin{array}{l}\text { - } \\
\text { - } \quad \text { Abertura da cessão onerosa. } \\
\text { - Lançamento primário de novas ações. }\end{array}$ & - $\quad$ Pós-crise financeira mundial. \\
\hline 2011 & - Congelamento de preço dos combustíveis. & - $\quad$ Aumento no preço do Brent. \\
\hline 2012 & - $\quad$ Política de congelamento permanece. & - $\quad$ Preço do Brent em alta. \\
\hline 2013 & - $\quad$ Entra nas investigações da Polícia Federal. & $\begin{array}{l}\text { - Manifestações de rua para redução das tarifas dos preços } \\
\text { dos transportes públicos. }\end{array}$ \\
\hline 2014 & $\begin{array}{ll}\text { - } & \text { Atraso na divulgação do balanço. } \\
\text { - } & \text { Lava Jato. } \\
\text { - } & \text { Desvalorização de Ativos (Impairment). } \\
\text { - } & \text { Prejuízos na empresa de R } \$ 21,9 \text { bilhões. }\end{array}$ & $\bullet$ \\
\hline 2015 & $\begin{array}{l}\text { - } \quad \text { Divulgação do balanço de } 2014 . \\
\text { - } \quad \text { Divulgação das perdas com a Lava Jato, e } \\
\text { - } \quad \text { Prejuízçãos na empresa de } \mathrm{R} \$ 35,1 \text { bilhões. } \\
\text { - } \quad \text { Mudança na política de preços. } \\
\text { - } \quad \text { Prejuízos na empresa de } \mathrm{R} \$ 13,0 \text { bilhões. }\end{array}$ & $\begin{array}{l}\text { - } \quad \text { Queda no valor do barril de petróleo. } \\
\text { - } \quad \text { Dólar em alta. } \\
\text { - } \quad \text { Redução das notas das agências de classificação de risco. } \\
\text { - } \quad \text { Taxa Selic elevada. } \\
\text { - } \quad \text { Aumento do Risco-País. } \\
\text { - } \quad \text { Queda no valor do barril de petróleo. } \\
\text { - } \quad \text { Dólar em alta. } \\
\text { - } \quad \text { Impeachment. } \\
\text { - } \quad \text { Classificação de Risco-País recua. } \\
\text { - } \quad \text { Taxa Selic em alta e estável. }\end{array}$ \\
\hline 2017 & $\begin{array}{l}\text { - } \quad \text { Empresa volta a ter lucros. } \\
\text { - } \quad \text { Distribuição de dividendos. }\end{array}$ & - $\quad$ Redução progressiva da taxa Selic. \\
\hline 2018 & $\begin{array}{ll}\text { - } & \text { Empresa apresenta lucros crescentes. } \\
\text { - } & \text { Distribuiçãa de dividendos. }\end{array}$ & $\begin{array}{l}\text { - } \quad \text { Aumento no preço do Brent. } \\
\text { - } \quad \text { Greve dos caminhoneiros. } \\
\text { - } \quad \text { Eleições } 2018 .\end{array}$ \\
\hline 2019 & 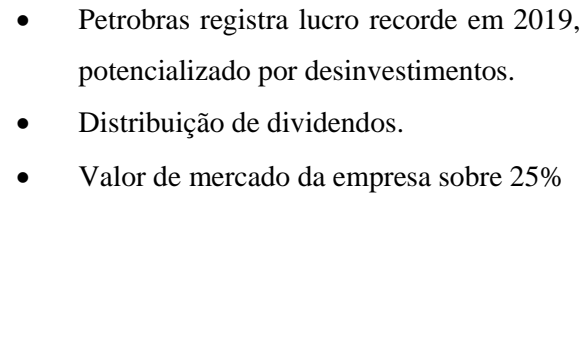 & $\begin{array}{l}\text { - } \\
\text { - } \text { milhão de barris por dia. } \\
\text { - } \quad \text { Qurte crescimento da Economia Chinesa. } \\
\text { - } \quad \text { Tensões no Oriente Médio. } \\
\text { - } \quad \text { Produção recorde de petróleo no Brasil. } \\
\text { - } \quad \text { Rápido ritmo de queda da SELIC. }\end{array}$ \\
\hline 2020 & $\begin{array}{l}\text { - } \quad \text { Mesmo com pandemia, Petrobras obteve } \\
\text { lucro líquido de } 7,1 \mathrm{Bi} \text { em } 2020 . \\
\text { - } \quad \text { Distribuição de dividendos. }\end{array}$ & 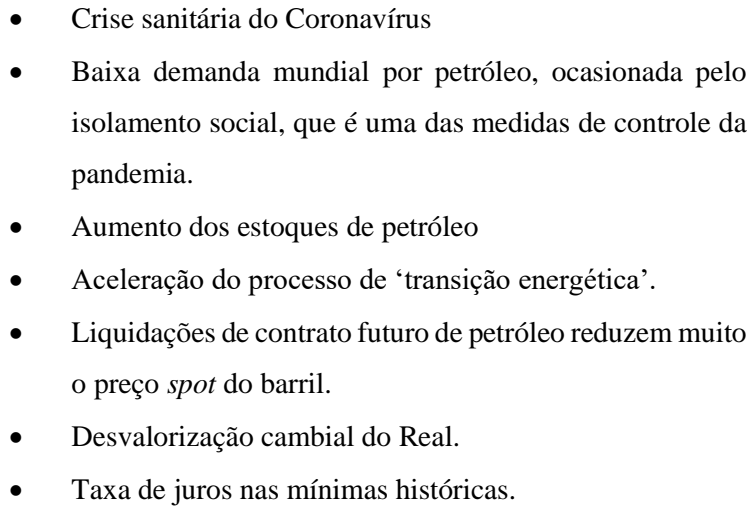 \\
\hline
\end{tabular}

Fonte: Elaborado pelos autores (2020). 
Em suma, é possível constatar que a precificação dos derivados (informada pelo preço do petróleo cru, do dólar e pela orientação do governo federal) desempenhou um papel relevante nas avaliações, de curto prazo, da empresa, bem como o comportamento das principais variáveis macroeconômicas, a greve dos caminhoneiros de 2018, a pandemia do Covid-19 e as mudanças nos lucros e na distribuição de dividendos.

A tabela 6, por seu turno, apresenta as correlações das variáveis utilizadas no estudo. Foi possível identificar que a ação PETR4 apresenta uma correlação positiva forte com o Ibovespa $(0,78)$, uma correlação positiva moderada $(0,45)$ com o S\&P 500 e uma correlação positiva (fraca) com o preço internacional do petróleo em dólares (BRENT US\$ = 0,36), explicado pelo fato do petróleo ser o principal produto de extração da Petrobras. Em contrapartida, a tabela 6 também permite identificar duas variáveis com correlação negativa fraca, em relação à variável PETR4, sendo elas o Dólar (-0,39) e o Risco-País (-0,37). Com base nesses resultados é possível afirmar que o preço das ações preferenciais da Petrobras, ao longo do período analisado, também foi afetado, consideravelmente, fatores internacionais.

Tabela 6 - Correlações das variáveis 2009/2020.

\begin{tabular}{|c|c|c|c|c|c|c|}
\hline & (PETR4) & $\begin{array}{l}\text { Índice } \\
\text { Bovespa }\end{array}$ & Selic & USD/BRL & EMBI+ & Brent (Fob). US\$ \\
\hline Índice Bovespa & 0,78 & & & & & \\
\hline Selic & $-0,01$ & 0,00 & & & & \\
\hline USD/BRL & $-0,39$ & $-0,49$ & $-0,06$ & & & \\
\hline $\mathrm{EMBI+}$ & $-0,37$ & $-0,46$ & 0,00 & 0,35 & & \\
\hline Brent (Fob). US\$ & 0,36 & 0,32 & $-0,03$ & $-0,20$ & $-0,26$ & \\
\hline Futuros S\&P 500 & 0,45 & 0,65 & 0,00 & $-0,42$ & $-0,46$ & 0,34 \\
\hline
\end{tabular}

Fonte: Elaborado pelos autores (2020).

Na sequência, serão analisadas, individualmente, cada uma dessas variáveis com uma abordagem qualitativa, de modo a contemplar aspectos que podem não ficar evidentes apenas com a observação isolada das estatísticas.

\subsection{Discussão dos Resultados cotejados com a Literatura}

Essa seção irá discutir os resultados das análises quantitativas aportando aspectos qualitativos. Ao longo dos 11 anos analisados a maior cotação das ações da PETR4 ocorreu no início do mês de dezembro de 2009, quando chegou a valer R\$ $31,19$. Já a sua menor cotação foi no início do ano de 2016, em que uma ação da empresa foi vendida por apenas $\mathrm{R} \$ 4,03$.

De acordo com Carvalho (2014), o mercado de ações, em geral, e o Ibovespa, em particular, podem ser determinados pelo próprio mercado de ações, como também pelo mercado de câmbio. Entre o período de 1999 e de 2012, foi constatado que a maior dependência do mercado acionário em relação ao cambial ocorre no período de crise, quando o movimento cerca de $50 \%$ da variação do Ibovespa pode ser explicada por alterações na taxa de câmbio. Segundo o autor, haveria uma relação unidirecional partindo da taxa de câmbio para o preço das ações (correlação positiva), o que confirmaria a abordagem tradicional de que depreciação cambial leva a valorização acionária, em contraposição à abordagem de portfólio que aponta o inverso.

Em seu trabalho, Majerowicz (2017) buscou verificar se houve efeito manada no mercado acionário brasileiro entre 2010 e 2015, período em que se verificou uma significativa instabilidade política, econômica e institucional no Brasil, manifesta em elevada volatilidade no índice Bovespa. $\mathrm{O}$ autor constatou, entretanto, que não houve indícios de um movimento nos moldes do "efeito manada" no referido período, ainda que o comportamento das variáveis macroeconômicas, em diferentes momentos 
neste intervalo de tempo, pudesse ter ensejado uma significativa aversão ao risco dos agentes econômicos, com momentos de rápida e intensa elevação do risco-país (EMBI+).

A próxima subseção trará a relação entre o preço da PETR4, os preços dos petróleos marcadores internacionais e a política de preços de derivados da Petrobras.

\subsubsection{Os Preços Internacionais do Petróleo e a Política de Preços da Petrobras}

É possível observar na figura 3 o movimento dos preços da ação PETR4 e do petróleo marcador Brent (US\$), os quais possuem certa sincronia, conformando a correlação positiva descrita anteriormente.

Figura 3 - Ações PETR4 x BRENT (US\$).

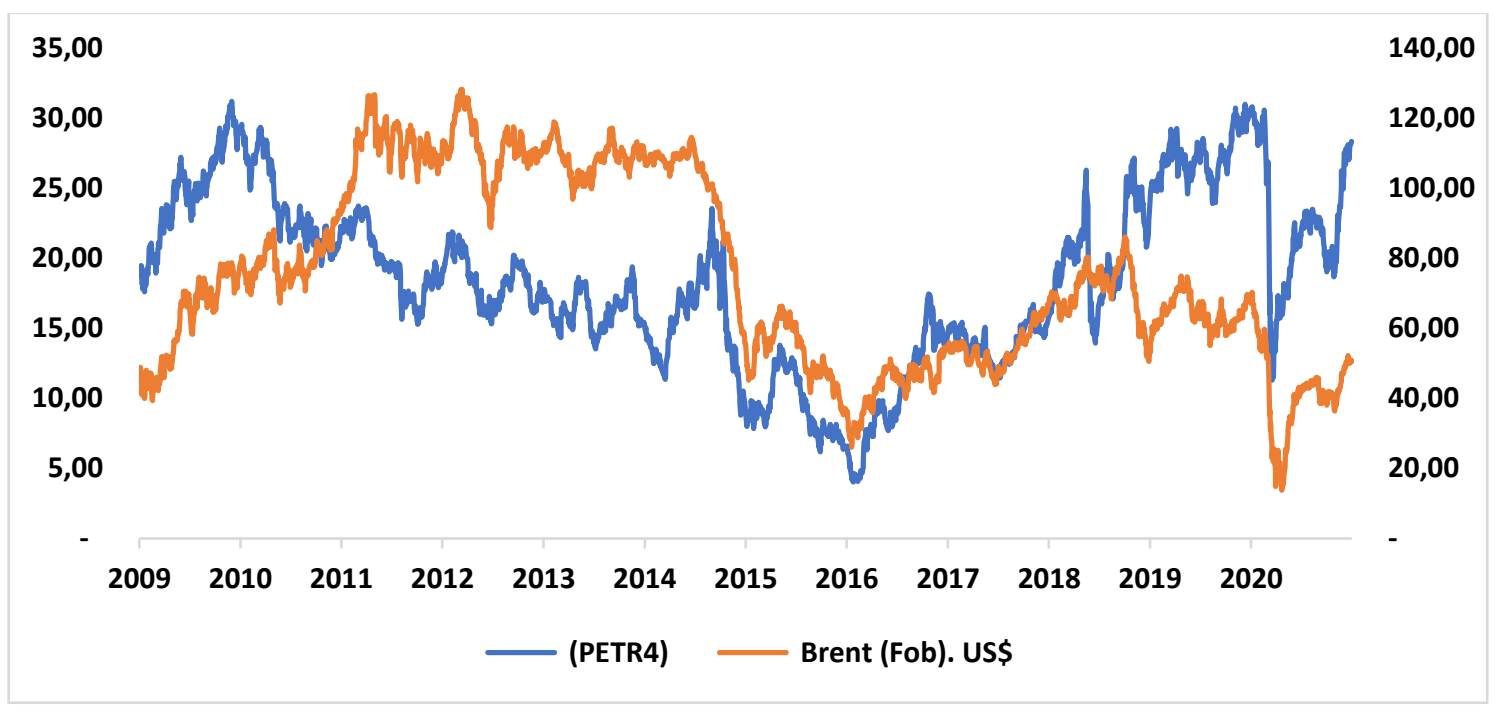

Fonte: Elaborado pelos autores (2020).

Santos (2015) aponta que alterações no preço internacional do barril de petróleo tendem a modificar a demanda e o estoque do produto de empresas que o ofertam, consequentemente, isso influencia o valor de seu ativo, de modo a promover mudanças no seu valor de mercado. No caso da Petrobras, é possível afirmar que o preço do Brent, em alguma medida, influenciou (e influencia) o preço de suas ações, conforme o resultado obtido a partir do cálculo de correlação. Cumpre notar que a partir de 2010 ocorre um descolamento entre essas duas variáveis, desde quando o valor da ação não acompanha, na mesma intensidade, o crescimento do preço do barril de petróleo, de maneira que, entre 2010 e 2015, verifica-se um período em que há um distanciamento significativo entre as referidas variáveis.

Na figura 4 são apresentadas as correlações verificadas em cada ano, que oscilaram entre $+0,28$ e $+0,41$. É justamente a partir do ano de 2010, quando ocorre uma forte variação do preço do Brent, que é reduzida a alta correlação positiva do ano anterior, a qual oscila até o ano de 2014. Este fenômeno é explicado pela política de preços dos combustíveis, uma vez que, neste período, o governo federal implementou uma política de estabilidade dos preços dos combustíveis para conter a alta inflação que o país enfrentava. O prejuízo foi absorvido pela Petrobras, que sofreu uma queda da lucratividade por seus preços não acompanharem as variações do preço internacional do barril de petróleo. Em verdade, historicamente, é recorrente as tentativas do governo federal (mesmo dos diversos matizes ideológicos) de influenciar a precificação dos combustíveis tendo em vista a sua importância na estrutura de custos de produção e de transporte e, portanto, na inflação do país. 
Figura 4 - Correlação PETR4 x BRENT.

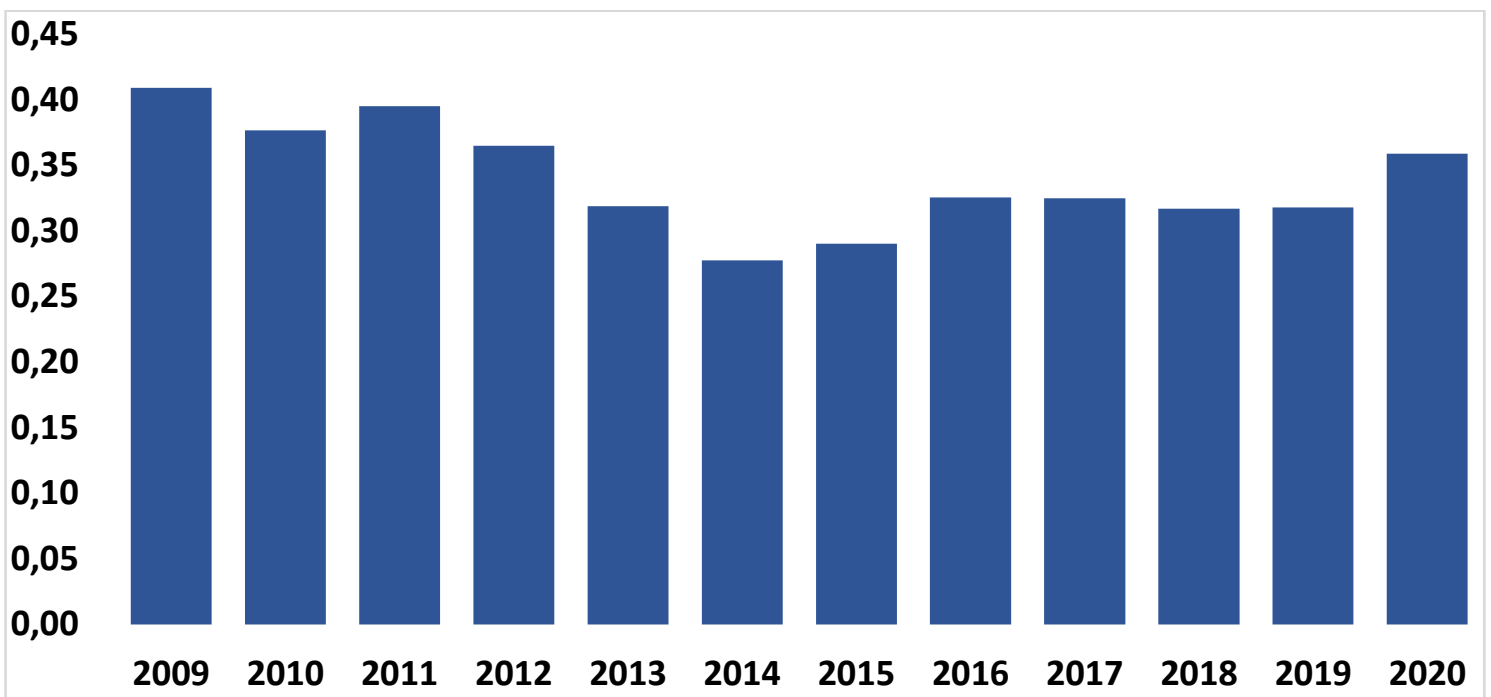

Fonte: Elaborado pelos autores (2020).

A política de preços da Petrobras diz respeito ao modelo econômico de precificação de derivados da empresa, que é de interesse tanto dos acionistas minoritários quanto do acionista majoritário (União). Tal política passou por importantes mudanças ao longo do período analisado, em especial, pelo fato das principais decisões estratégicas, que influenciam diretamente a produção, os investimentos e o lucro da empresa precisarem do aval do Conselho Administrativo, que é composto também por membros indicados pelo acionista majoritário (União). Por essa razão, as orientações do governo federal são determinantes para política de preço dos combustíveis da empresa.

É possível então dizer que existem duas forças que pressionam a empresa a tomar suas decisões: i) uma delas pode envolver objetivos de política pública (econômico-sociais ou populista-eleitoreiros) por se tratar de uma empresa de economia mista e; ii) outra orientada à geração de lucro, que é um dos principais objetivos de uma empresa.

O período de análise deste estudo tem início no terceiro ano do segundo mandato de Luiz Inácio Lula da Silva (2003 a 2010), no qual se verificou uma política de preços voltada para um dos objetivos do Estado: o desenvolvimento econômico. Na prática, aquele governo adotou uma política de conteúdo local e uma de preços dos derivados que priorizaram o desenvolvimento do País, sem comprometer, apenas num primeiro momento, a capacidade de investimentos da Petrobras. Como o petróleo é uma commodity, o preço do barril é definido pelo mercado internacional. Vale lembrar que, em 2008 ele chegou a atingir a sua maior cotação da história.

Diante do boom das commodities o governo de Luiz Inácio Lula da Silva adotou uma política de estabilidade nos preços dos combustíveis comercializadas internamente no Brasil. Com base nela, os reajustes ocorriam com pouca periodicidade, sob o argumento de amortecer rápidas e fortes altas ou significativas reduções do preço da commodity no mercado internacional. A tendência de valorização da taxa de câmbio, pós-crise de 2008, também ajudou a conter os preços de derivados no Brasil. Essa estratégia teve um resultado de ajudar a conter a inflação de custos no Brasil, tendo em vista a importância dos combustíveis (em especial o diesel e a gasolina) nesse indicador macroeconômico.

Esta política foi intensificada nos governos Dilma Rousseff (2011 a 2015), com o propósito mais explícito de combate à inflação, o que acabou por gerar graves consequências, a exemplo do forte aumento do endividamento da Petrobras, num contexto em que o seu ritmo de investimentos era acelerado. Segundo Almeida et al (2015), desde 2011 a empresa acumulou prejuízos importando gasolina, diesel e GLP, em especial, na medida em que vendia, internamente, por valores inferiores aos 
preços de aquisição no mercado internacional. Isso comprometeu a capacidade de investimento, de crescimento e de geração de valor da Petrobras, além de reduzir a atratividade das suas ações da empresa no mercado financeiro.

De acordo com Viegas e De Paula (2018), contextos desfavoráveis de custos e preços (internacionais) relativamente baixos do petróleo, podem comprometer a economicidade de projetos de E\&P (inviabilizá-los ou adiá-los). Destaca-se que aumentos de preços da commodity também elevam os custos devido à considerável correlação entre essas duas variáveis, em especial na direção crescente. Isso ocorre pelo fato de que investimentos de capital é intensiva em aço, de modo que os ciclos de preços das commodities afetam custos e preços do petróleo. Ademais, aumentos de preços do petróleo tendem a elevar, consideravelmente a demanda por serviços, máquinas e equipamentos do setor de E\&P, gerando inflação de custos no Upstream da atividade petrolífera.

Em maio de 2016, ao assumir a presidência da Petrobras, Pedro Parente se comprometeu a ajudar a recuperar o lucro da empresa e mudou a política de preços, a qual teria dois fatores como base fundamental. O primeiro se referia à paridade com o mercado internacional e o segundo seria uma margem para remunerar riscos inerentes à operação da empresa. Além disso, essas alterações incluíam reajustes pelo menos uma vez por mês (Petrobras, 2016).

Em 2017, a Petrobras anunciou que haveria aumento na frequência dos reajustes, motivada pelas altas na taxa de câmbio e nas cotações do petróleo. Após dois anos de recordes nos seus patamares mínimos, o preço do petróleo voltou a subir no mercado internacional. Em julho daquele ano, os reajustes estavam sendo realizados quase que diariamente. Em dezembro, a gasolina bateu pela primeira vez a marca de $\mathrm{R}$ \$,00 nas bombas de combustíveis (MOura, 2018). Os reajustes diários também buscaram reduzir a capacidade de arbitragem dos importadores, que tinham um melhor horizonte de cálculo quando as mudanças nos preços dos derivados ocorriam numa frequência menor.

Contudo, os efeitos colaterais dessa política se evidenciaram em 2018, diante da maior frequência dos reajustes e das significativas (e constantes) altas nos preços dos combustíveis. Neste contexto, os caminhoneiros realizaram uma greve da categoria, de grandes proporções, que praticamente parou o setor de transportes (rodoviários, em especial) do país. Entre as bandeiras da categoria estava a redução do preço do diesel, além da valorização do frete (que se manifestou na chamada "Tabela de Frete"), com base no argumento de que a atividade dos caminhoneiros estava inviável no país. As consequências da greve foram inúmeras, tanto para quem produzia, quanto para quem consumia, pois faltaram insumos nas indústrias, não havia transporte de mercadorias do campo, de modo que muitos produtos pereceram antes de chegar ao seu consumidor de destino.

A partir de então, o valor das ações da Petrobras começou a se descolar novamente dos preços dos petróleos marcadores internacionais (Brent e WTI, por exemplo), ou seja, havia os indícios de que a pressão política para conter preços dos combustíveis poderia se manter elevada ao longo do governo Temer, presidente à época. O governo Bolsonaro, por seu turno, teve de enfrentar o mesmo dilema: i) manter uma política de preços de paridade com as cotações internacionais ou; ii) seguir uma direção mais populista, com mais aderência à pauta dos caminhoneiros e de setores da sociedade que desejam preços mais baixos dos derivados do petróleo. Diante desse debate, o governo federal substituiu a presidência da Petrobras, no ano de 2021, e foram lançadas dúvidas sobre a propensão do governo federal a adotar uma trajetória aderente com a segunda opção (entre as supramencionadas).

\subsubsection{A influência da cotação do dólar no preço da PETR4}

Em tese, é esperado uma correlação positiva entre taxa de câmbio e o preço da PETR4 por motivos tais como, por exemplo: i) o petróleo é uma commodity cotada em dólar; ii) a Petrobras exporta óleo cru e; iii) os preços dos derivados vendidos no Brasil são, em algum grau, mediados pela taxa de câmbio. Contudo, nem sempre, essa relação entre tais variáveis é verificada. Na prática, em alguns momentos da história recente essa relação foi no sentido contrário, ou seja, elevações na taxa de câmbio estiveram associadas a queda no preço das ações, como se pode observar na figura 5. 
Isso pode ser explicado por algumas razões, a exemplo de: i) relação imbricada entre preços do petróleo e os custos enfrentados pelo setor petrolífero, se explica, entre outros motivos, pelo fato de que aumentos na cotação da commodity tendem a viabilizar novos projetos de Exploração e Produção (E\&P) de hidrocarbonetos, de modo a elevar a demanda por bens e serviços parapetrolíferos e os seus respectivos preços (Viegas \& de Paula, 2018); ii) o elevado endividamento da Petrobras, pois grande parte dele está fixado em dólar. Logo, quanto mais cara estiver à moeda americana, mais alta a dívida tenderá a ser.

Figura 5 - Ações PETR4 x DÓLAR.

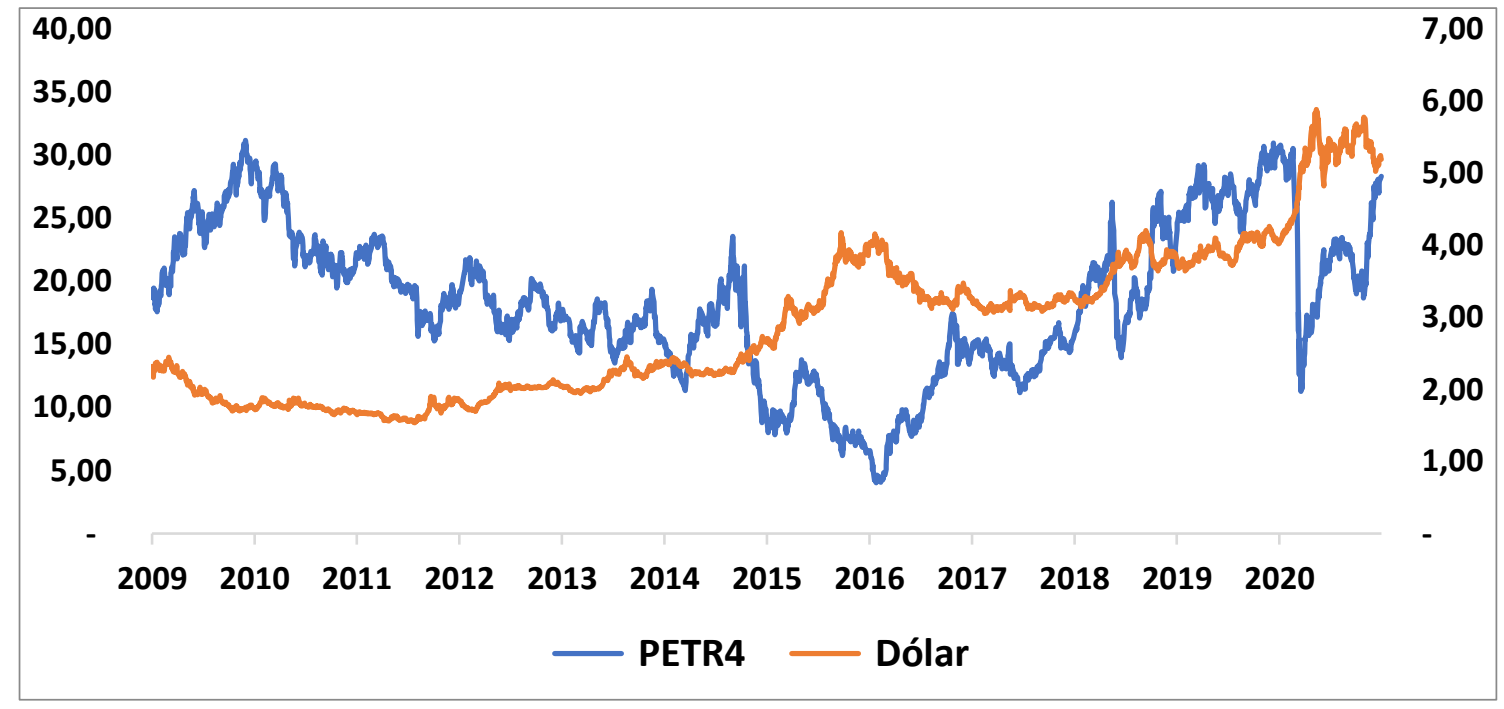

Fonte: Elaborado pelos autores (2020).

Neste sentido, Doornik (2007) constatou uma correlação positiva moderada entre a variável taxa de câmbio e o passivo circulante da empresa Petrobras. $\mathrm{O}$ autor atribui este resultado à alta dependência de empréstimos externos de curto prazo (ou obrigações com fornecedores do exterior), enfrentada pela Petrobras no período analisado.

Outro aspecto que pode afetar o preço das ações é o indicador EMBI+ (Emerging Markets Bond Index Plus), criado pelo JP Morgan, que sintetiza o desempenho dos títulos emitidos em países emergentes como o Brasil. Esta relação será explorada na seção a seguir.

\subsubsection{A influência do EMBI+ (Risco-Brasil) no preço da PETR4}

Há uma relação entre mercados de ações destes países também é mediada pelo desempenho do Risco-País de determina economia. É possível notar a partir da Figura 6 que o comportamento da PETR4, não raro, segue um sentido inverso daquele apresentado pela EMBI+, ou seja, quanto maior o risco-país, menor tende a ser (em algum grau) o preço da ação da Petrobras. Doornik (2007) também utilizou a variável Risco-País em seu trabalho e, analogamente, tal variável se mostrou correlacionada ao passivo circulante da Petrobras. No entanto, o referido autor atribui o resultado à forte ligação deste último com a taxa de câmbio e obteve resultados compatíveis com os deste artigo. 
Figura 6 - Ação PETR4 e EMBI+ (RISCO-PAÍS).

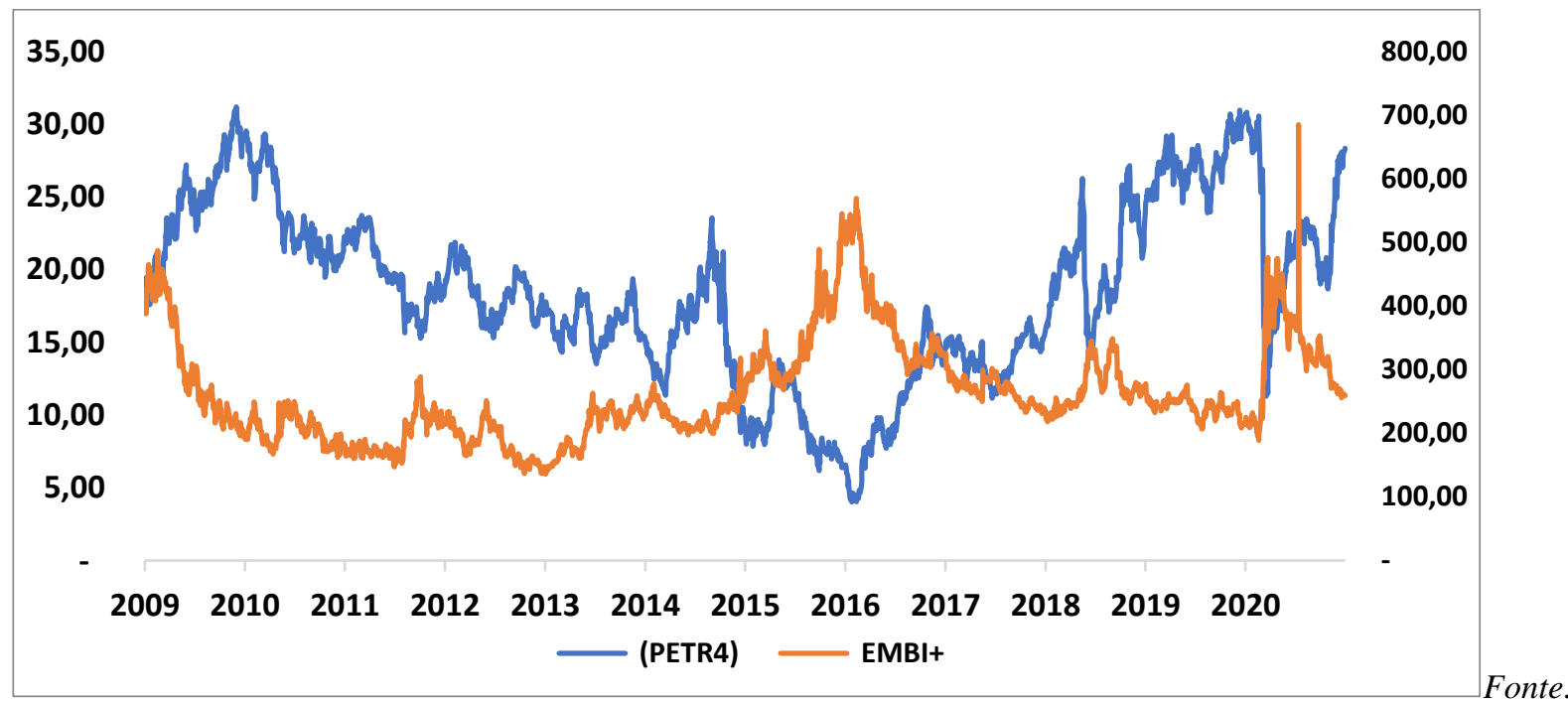

Elaborado Fonte: Elaborado pelos autores (2020).

A correlação entre PETR4 e EMBI+ varia de -0,37 e corresponde uma correlação negativa moderada. Como se pode notar na Figura 7, a correlação ano a ano das variáveis oscilou entre -0,37 e -0,48. O EMBI+ é uma referência importante para os investidores estrangeiros, que, historicamente, movimentam volumes significativos de recursos na B3. Tanto o preço da ação da Petrobras como o EMBI+ apresentaram o maior patamar de estresse no ano de 2016, quando a correlação entre essas duas variáveis foi fortemente negativa. Foi um momento em que tanto o risco da empresa quanto o risco associado ao País atingiram níveis considerados elevados.

Figura 7 - Correlação PETR4 x EMBI+ (RISCO-PAÍS).

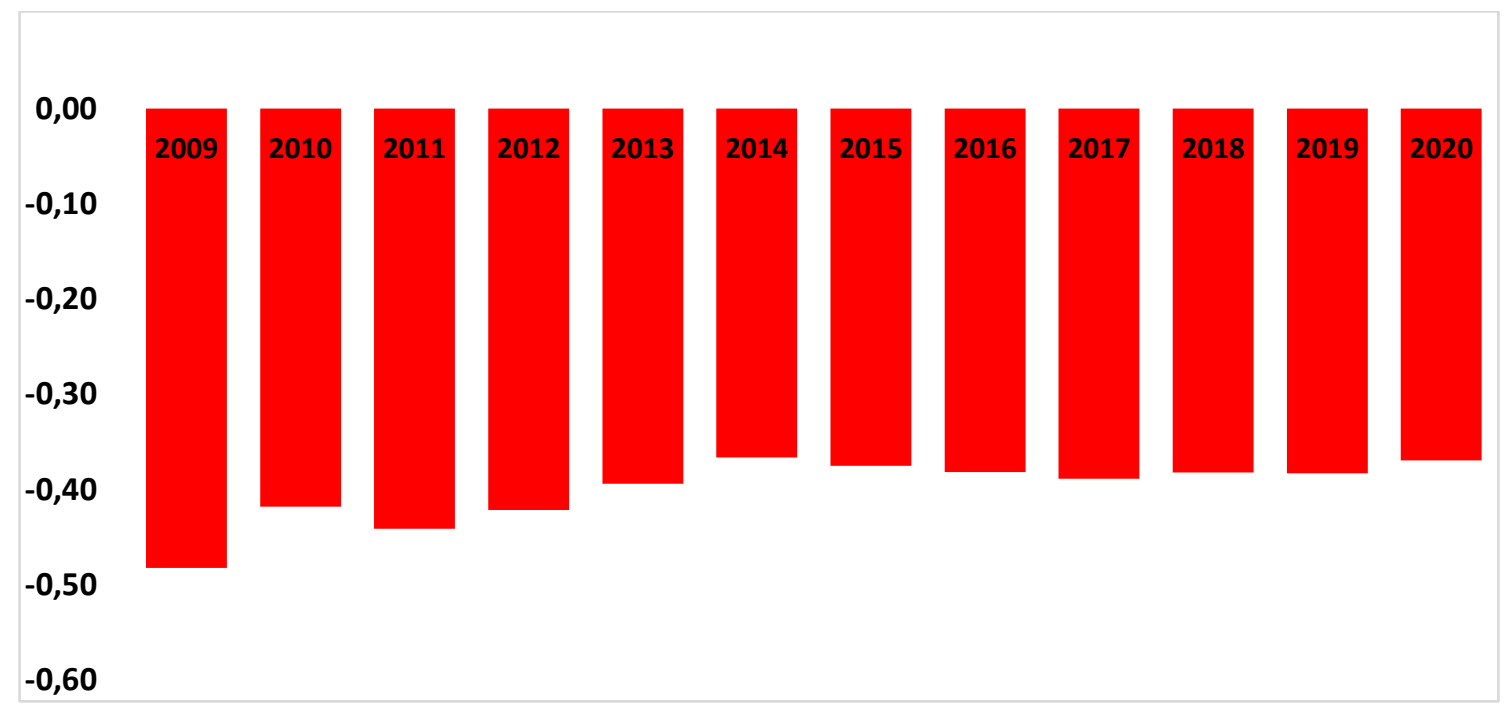

Fonte: Elaborado pelos autores (2020).

Na seção a seguir será abordada a correlação entre Ibovespa e PETR4. 


\subsubsection{A influência do Ibovespa no preço da PETR4}

É significativa a correlação entre PETR4 e o Ibovespa, ao longo da totalidade do período analisado, como pode ser observado na Figura 8. Essa relação se manifesta por duas vias. Por um lado, as ações da Petrobras correspondem a um percentual (atualmente 7\%) significativo do índice Bovespa, ou seja, exerce influência nos movimentos do índice. Por outro lado, o desempenho deste indicador também é um termômetro do mercado acionário brasileiro que afeta, consideravelmente, a propensão a comprar e vender (demanda e oferta) dos agentes econômicos sobre as ações, de modo a afetar, em alguma medida, os seus preços. O Ibovespa chegou ao seu pico histórico no início do ano de 2020, próximo dos 120.000 pontos. Ao longo destes anos, em contrapartida, a sua pior posição foi no início de março de 2009, quando fechou o dia em 36,2 mil pontos.

Figura 8 - Cotação PETR4 x IBOVESPA

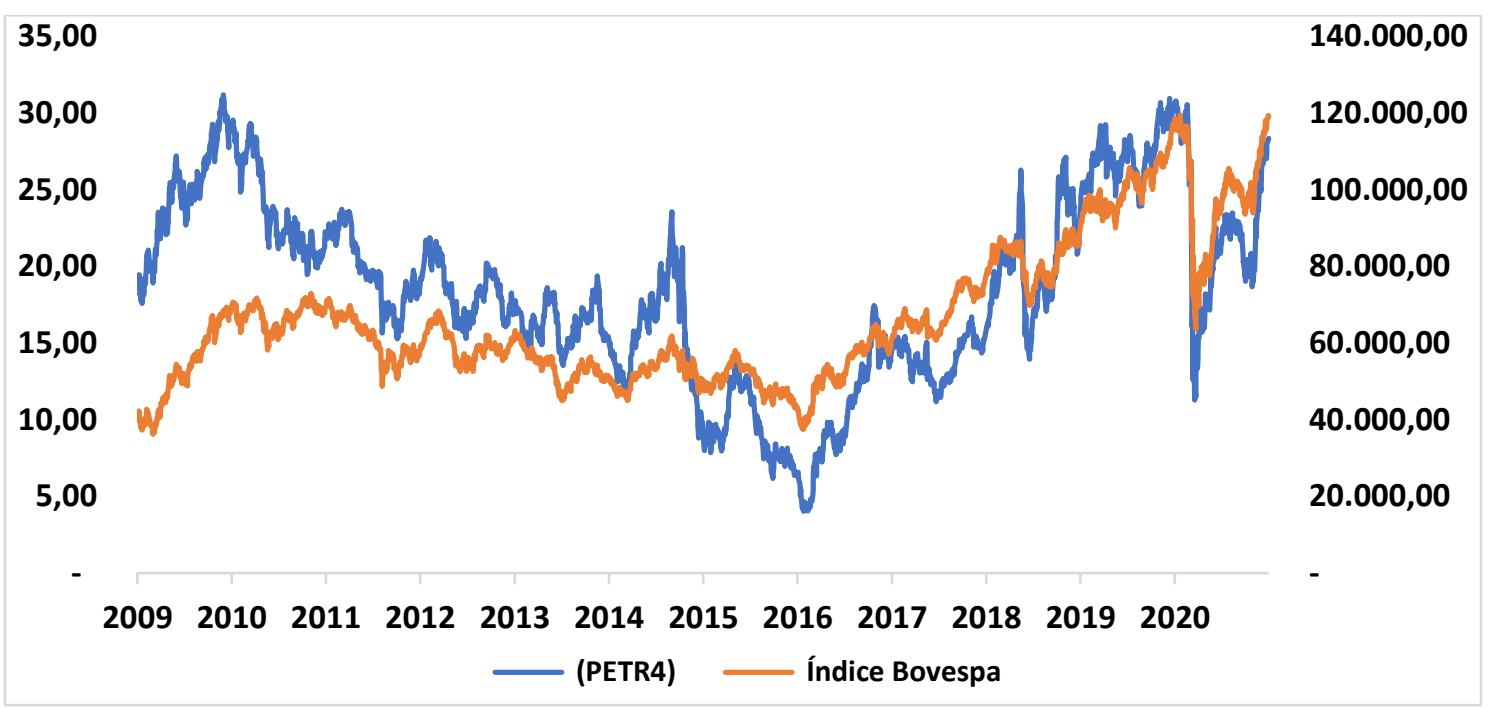

Fonte: Elaborado pelos autores (2020).

Naturalmente, o comportamento do preço da ação da Petrobras também guarda relação com os fundamentos microeconômicos da própria empresa, a exemplo do seu resultado financeiro, que será discutido na próxima seção.

\subsubsection{A influência do Lucro/Prejuízo Líquido no preço da PETR4}

Os resultados identificados na figura 9, apresentam o Lucro/Prejuízo Líquido da Petrobras ao longo do período. Após saldos crescentes até o ano de 2010, a empresa iniciou um ciclo de quedas, chegando a acumular prejuízos em três anos sequentes (2014, 2015 e 2016). A partir do ano de 2017 a empresa começou a registrar resultados positivos e isso também passa a se manifestar positivamente nos preços da ação.

Os anos de 2010 e 2011 marcam o início de um ciclo de redução do potencial de lucro da Petrobras, o que coincide com a mudança na política de preços dos combustíveis, bem como uma aceleração do ciclo de investimentos de capital em projetos capital-intensivos. A tendência de redução do resultado líquido da empresa atingiu o seu ápice nos anos de 2014 e 2015, no auge das denúncias de corrupção e investigações no âmbito da operação Lava Jato, conformando escândalos políticos. Este contexto evidenciou ainda mais as mazelas das intervenções políticas desonestas e ineficientes em empresas estatais, as quais desencadearam um significativo retrocesso da Petrobras e a queda no preço de suas ações na bolsa. Outro efeito colateral da operação Lava Jato foi desestruturar grande parte do setor de construção civil brasileiro e, consequentemente, impactar negativa e significativamente o crescimento econômico do Brasil. Por essa razão, o desempenho em forma de lucro da Petrobras teria sido ainda mais penalizado. 
Figura 9 - Lucro/Prejuízo Líquido Petrobras, em milhões de Reais.

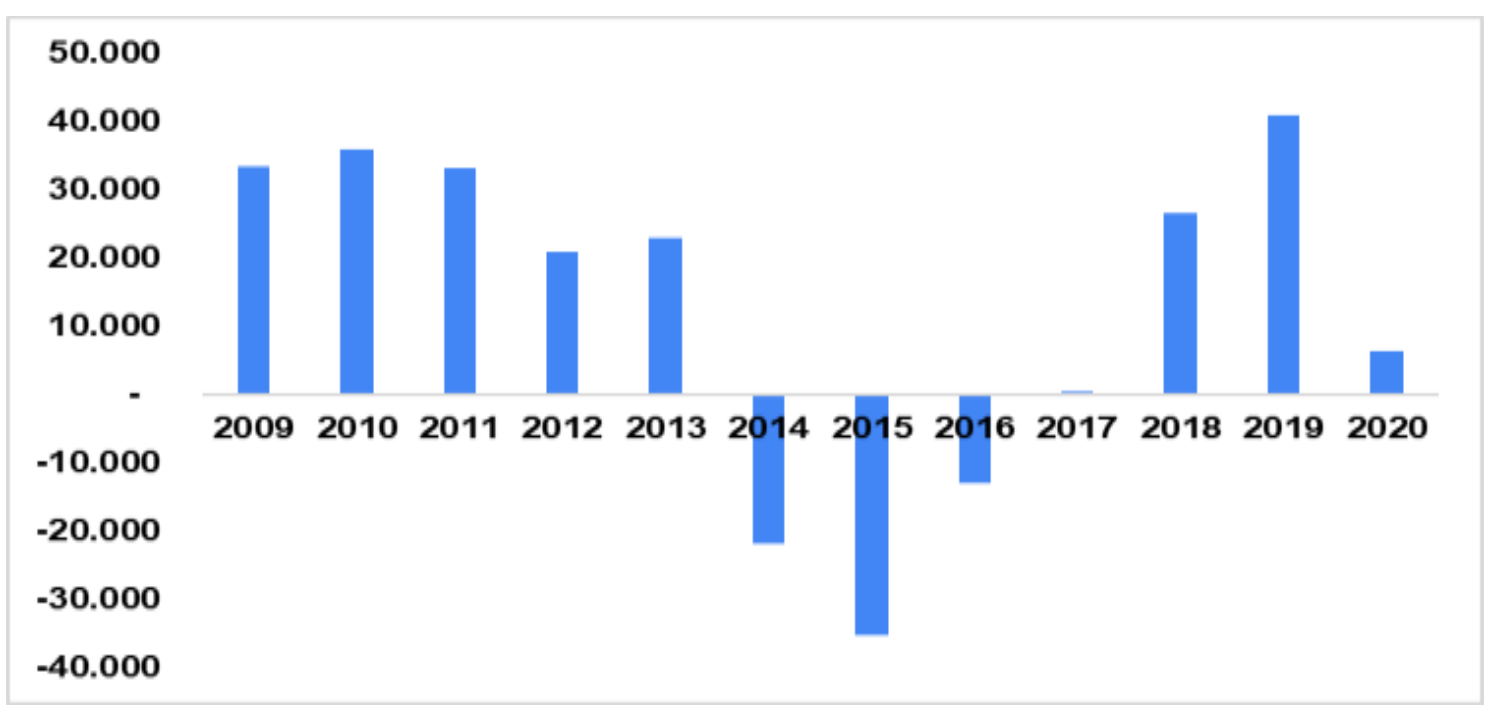

Fonte: Elaborado pelos autores (2020).

Partes dos prejuízos acumulados em 2014 se referem a uma sequência de fatores. Segundo Almeida et al. (2017) os impairments ${ }^{1}$ foram responsáveis por cerca de $\mathrm{R} \$ 44,6$ bilhões, e $\mathrm{R} \$ 6,2$ bilhões decorrentes dos pagamentos indevidos no âmbito da Lava Jato. Além disso, o referido autor abordou as agências de classificação de risco que consideraram tanto os escândalos políticos (que envolvem a empresa), quanto as demonstrações de resultado do exercício, as quais apresentaram lucro apenas no primeiro ano, no período de 2013 a 2016, pois nos outros anos (desse conjunto) ela registrou apenas resultados negativos. Diante disso, no ano de 2015 as três principais agências de classificação de risco rebaixaram as notas da Petrobras, começando em fevereiro com a Moody's. Em setembro foi vez da Standard \& Poor's (S\&P). Ao final do ano foi a vez da Fitch. Estas notas levaram a empresa à condição de "grau especulativo", o que corresponde a uma empresa com dificuldade para arcar com seus compromissos financeiros. No caso da Petrobras, o grau especulativo estaria associado aos prejuízos acumulados e ao elevado endividamento em dólares.

Segundo o trabalho de Martins et al. (2015), a partir de demonstrações financeiras, divulgadas e publicadas em jornais, apontou um crescimento na dívida líquida da Petrobras, saindo de $\mathrm{R} \$ 40,95$ Bilhões, em 2011, para cerca de $\mathrm{R}$ \$ 261 bilhões em 2015. O autor aponta fatores como: (i) necessidades de investimentos; (ii) dívida maior que os lucros; (iii) operação Lava Jato; (iv) falta de credibilidade; (v) escândalos dentro da empresa; (vi) notificações de irregularidades; (vii) problemas de gestão; (viii) entre outros, como responsáveis pelos resultados da empresa.

Segundo Sales e Nunes (2017), a Petrobras passou por várias transformações econômico-financeiras, desde a sua fundação até a atualidade. $\mathrm{O}$ advento das reservas gigantes contidas no Pré-sal, a empresa executou um programa audacioso de investimentos, envolvendo parcerias públicas e privadas, financiamento internacional e nacional, com o objetivo de criar condições tecnológicas e financeiras para colocar em marcha mega projetos de E\&P de grandes reservas em águas profundas. Contudo, a queda acentuada do preço do petróleo (reduziu as receitas da empresa) e a crise de governança (que gerou problemas financeiros e jurídicos) comprometeram, sobremaneira, os resultados da empresa, os quais não refletiram as projeções feitas nos primeiros anos do período 2010-2015.

Segundo cálculos de Sales e Nunes, entre 2010 e 2016, os índices de sustentabilidade financeira da Petrobras oscilaram em patamares classificados como de sustentabilidade baixa ou sustentabilidade desprezível, mas ainda assim, os índices da

${ }^{1}$ Impairments: é uma palavra em inglês que significa, em sua tradução literal, deterioração. 
Petrobras ainda foram melhores do que de outra grande petroleira Internacional a Shell, por exemplo. Quanto ao indicador de insolvência, a Petrobras esteve na pior classificação entre os pares analisados (Chevron, Petrobras e Shell), uma vez que, ao longo do período supramencionado, ela esteve na denominada zona de risco, ou seja, ela apresentava um risco de falência não negligível. Por outro lado, é preciso dizer que uma empresa de economia mista como a Petrobras, teoricamente, apresenta menos riscos de falir pela possibilidade de receber aportes de capital da União.

Na próxima seção será abordada a relação entre taxa básica de juros e o comportamento do Ibovespa.

\subsubsection{A influência da SELIC no Ibovespa}

Outros resultados importantes a considerar, a partir do método de correlação de Pearson, dizem respeito à relação Ibovespa e Taxa de juros (Selic), principalmente no ano de 2017, quando a política monetária do País esteve mais ativa, foi identificado uma correlação negativa forte (-0,78), a Figura 10 apresenta a trajetória dessas duas variáveis ao longo do período analisado.

Figura 10 - Evolução Ibovespa e Selic.

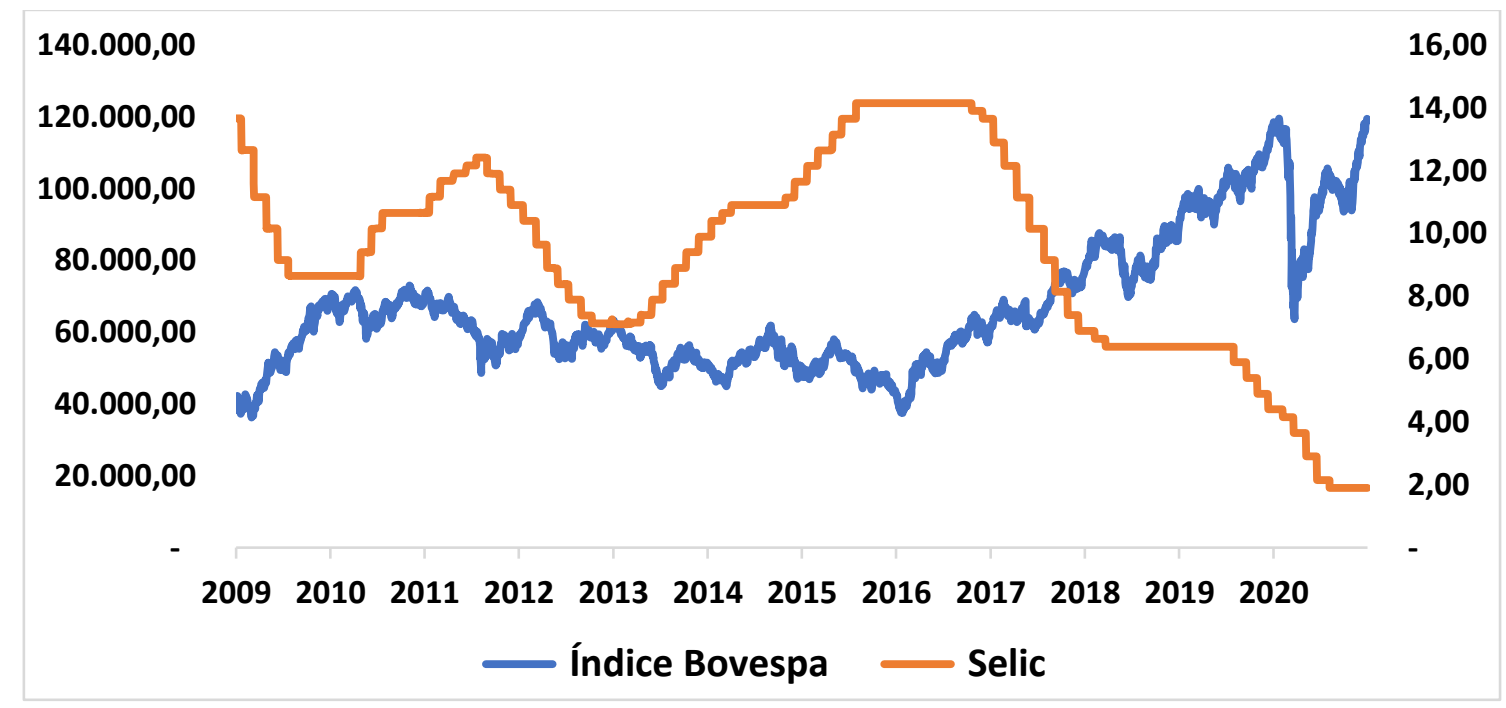

Fonte: Elaborado pelos autores (2020).

É possível observar claramente a relação inversa dessas duas variáveis, o que confirma a hipótese de que uma redução na taxa básica de juros aqueceria os mercados de renda variável, pois o investidor procura a maior rentabilidade possível à medida que a renda fixa deixa de ser atrativa.

Conforme trabalho de Linck e Decourt (2016), que analisou dados de 2000 a 2010, a relação entre as variáveis macroeconômicas e as variações dos preços das ações apresenta resultados diferentes dependendo da localização e do momento do tempo em que se analisa. A taxa básica de juros e o patamar de crescimento do PIB afetam os preços das ações, mas a inflação e as expectativas de mercado sobre o comportamento futuro destas variáveis afetam os preços de forma insignificante.

Já no estudo de Monteiro et al. (2016) foi possível identificar que as variáveis produto interno bruto (PIB), taxa de juros são cointegrados ao Ibovespa, tendo uma relação de longo prazo entre elas. Já à taxa de câmbio, a taxa de juros e o PIB, exercem certa influência sobre o Ibovespa.

Na próxima seção serão resumidas as considerações finais deste artigo. 


\section{Considerações Finais}

Este trabalho objetivou identificar as variáveis que impactaram, com maior intensidade, as ações preferenciais da Petrobras (PETR4), no período de 2009 à 2020, utilizando o método de correlação de Pearson e o método de MOQ, por meio dos quais foi identificado quais as variáveis internacionais foram as que tiveram maior influência no preço da referida ação.

Entre os principais resultados obtidos a partir dos cálculos de correlação envolveram o preço do barril de petróleo em dólares (Brent, em US\$), a taxa de câmbio (Dólar), a taxa de juros, o EMBI+ (Risco-País), a produção de barris de petróleo pela Petrobras e o Ibovespa (Ibov). Os resultados econométricos apontaram que, dentre estes, apenas o preço do barril de petróleo, o índice Ibovespa e a produção de petróleo pela Petrobrás se mostraram estatisticamente significativos. Assim, pode-se dizer que o aumento de US\$ 1 no preço do barril do petróleo no mercado internacional impacta no aumento de R\$ 0,028 na ação PETR4. $\mathrm{O}$ aumento de 1 ponto do índice Ibovespa impacta no aumento de $\mathrm{R} \$ 0,0003$ na ação da Petrobras. Por fim, o aumento da produção de mil barris de petróleo impacta na queda do valor da ação PETR4 em R \$ 0,018. O modelo estimando, por seu turno, explica em $60,13 \%$ as variações da ação da Petrobrás.

Além das análises quantitativas, observou-se, também a influência de fatores qualitativos, ou seja, aqueles que não se manifestam em estatísticas diárias, mas sim eventos econômicos, políticos, sociais ou da natureza, que podem causar muita influência no valor das ações, tais como aqueles descritos ao longo do trabalho. Entre os principais elementos estão: i) Política de preço dos combustíveis; ii) Cenário Político (decisões ou manifestações políticas); iii) Indicadores financeiros da empresa; iv) Notas das agências de classificação de risco; v) Operação Lava Jato; vi) variáveis microeconômicas de influência no preço da ação.

Por fim, as evidências empíricas sugerem que, não apenas, variáveis de mercado influenciaram significativamente as ações da Petrobras, mas também aspectos políticos associados, por exemplo, ao intervencionismo indevido do governo federal na gestão e nos preços da Petrobras. É preciso destacar que a Petrobras é uma empresa estatal (de economia mista). Por isso, esses fatores podem distorcer quaisquer tendências ou forças essencialmente de mercado, uma vez que um cenário negativo pode ser amenizado ou agravado por fatos políticos que, não raro, geram impactos no preço dessa ação, para além daqueles intrínsecos ao desempenho da empresa, em particular, ou da economia nacional, em geral.

A proposta de pesquisa encaminhada por este trabalho se destaca por contribuir para o enriquecimento da literatura empírica que trata da influência dos fatores macroeconômicos e institucionais para os preços das ações das empresas do ramo petrolífero, em geral, e da Petrobrás, especificamente. Entretanto, tal proposta não se encerra neste trabalho. É fundamental continuar a pesquisa, utilizando métodos sofisticados de investigação econométrica para análise de séries temporais, o que é pretendido ser feito em trabalhos futuros.

Para futuras pesquisas, os autores sugerem a utilização de modelos mais sofisticados, com a possível introdução, no estudo, de empresas (estrangeiras) do mesmo setor, de modo a buscar identificar as variáveis que influenciam o preço das ações destas organizações. Outro possível recorte analítico passa por analisar, mais especificamente, a influência das decisões do governo federal nos preços das ações da Petrobras.

\section{Referências}

Almeida, A. A., Silva C. A. \& Batista, W. J (2017). Análise elementar econômico-financeira da Petrobrás: um estudo sobre as demonstrações financeiras publicadas entre os anos 2013-2016. XIV Simpósio de Excelência em Gestão e Tecnologia - SEGeT’2017. https://www.aedb.br/seget/arquivos/artigos17/28425394.pdf.

Almeida, E. L. F., Oliveira, P. V. \& Losekan, L. L (2015). Impactos da contenção dos preços de combustíveis no Brasil e opções de mecanismos de precificação. Rev. Econ. Polit. 35(3). http://dx.doi.org/10.1590/0101-31572015v35n03a09.

Amorim, F. R., Oliveira, S. C. \& de Andrade, A. G. (2020). Fatores significativos aos preços de ações das principais empresas do setor sucroenergético do Brasil. Research, Society and Development, 9(9). 
Research, Society and Development, v. 10, n. 7, e13410716294, 2021

(CC BY 4.0) | ISSN 2525-3409 | DOI: http://dx.doi.org/10.33448/rsd-v10i7.16294

Assaf Neto, A (2018). Mercado Financeiro. 14ª ed. São Paulo: Atlas.

Azevedo, R., Ryngelblum, I (2019). Itaú desbanca Ambev como maior empresa em valor de mercado da B3. Valor Econômico. https://www.valor.com.br/empresas/6049655/itau-desbanca-ambev-como-maior-empresa-em-valor-de-mercado-da-b3.

Bernardo, C. J., Albanez, T. \& Securato, J. R. (2018). Fatores Macroeconômicos e Institucionais, Composição do Endividamento e Estrutura de Capital de Empresas Latino-Americanas. BBR. Brazilian Business Review, 15(2), 152-174.

Carvalho, L. F. (2014). Ensaios sobre volatilidade: taxa de câmbio, investimento estrangeiro, governança corporativa e preços de ações. Tese de Doutorado em Economia. Universidade Federal de Uberlândia.

Costa, A. S (2016). O Marco Regulatório da Indústria de Petróleo e Gás Natural no Brasil Sob o Prisma do Regime de Informação. Escola de Comunicação, UFRJ.

http://ridi.ibict.br/bitstream/123456789/950/1/O\%20marco\%20regulat\%C3\%B3rio\%20da\%20ind\%C3\%Bastria\%20de\%20petr\%C3\%B3leo\%20sob\%20o\%20 prisma\%20do\%20regime\%20de\%20informa\%C3\%A7\%C3\%A3o.pdf.

Doornik, B. F. N. V (2007). Modelagem econométrico-financeira de uma empresa baseada em vetores auto-regressivos: uma aplicação à Petrobrás S.A. $177 f$. Dissertações (Mestrado em Administração) -Universidade de Brasília. http://bdtd.ibict.br/vufind/Record/UNB_5138586400678d44931c43750713800b.

Faria, L. C. S. et al (2015). Impacto Da Governança Corporativa No Risco Da Empresa Petrobras. XII Simpósio de Excelência em Gestão e Tecnologia SEGeT'2015. https://www.aedb.br/seget/arquivos/artigos15/16922192.pdf.

Fortuna, E (2020). Mercado Financeiro; Produtos e Serviços. $22^{a}$ ed. Qualitymark.

Jesus Júnior, L. B., Sarti, F. \& Júnior, H. D. M. F. (2017). Petrobras: Política de Conteúdo Local, Natureza Jurídica, Governança Corporativa e Performance Econômica. Economic Analysis of Law Review, 7(2), 530-576.

Juaçaba, R. S. (2018). The Contingency effect of national culture on corruption: a comparative case study of Petrobras and Statoil. Dissertação de Mestrado em Globalização, Polítca e Cultura. Norwegian University of Science and Technology (NTNU).

Kahil, G (2018). B3: As ações mais negociadas em 2018. MoneyTimes. https://moneytimes.com.br/fast/as-20-acoes-mais-negociadas-em-2018/.

Linck, L. \& Frota Decourt, R. (2016). Stock returns, macroeconomic variables and expectations: Evidence from Brazil. Pensamiento \& gestión, (40), 91-112.

Lira, S. A (2004). Análise de correlação: Abordagem teórica e de construção dos coeficientes com aplicações. Universidade Federal do Paraná. http://www.ipardes.gov.br/biblioteca/docs/dissertacao_sachiko.pdf.

MacKinnon, J. G. (1996). Numerical distribution functions for unit root and cointegration tests. Journal of applied econometrics, 11(6), 601-618.

Majerowicz, Iuri (2017). Houve efeito manada no mercado de ações brasileiro entre 2010 e 2015-Uma análise a partir do modelo de CCK. Dissertação de Mestrado em Administração. PUC-Rio.

Martins, P. A. \& Rodrigues, M. C. F (2015). Impactos Sofridos Na Parte Contábil Da Empresa Petrobrás Após As Notificações Do Esquema Lava Jato. XII Simpósio de Excelência em Gestão e Tecnologia - SEGeT'2015. https://www.aedb.br/seget/arquivos/artigos15/35022388.pdf.

Monteiro, B. R. L. G. et al (2016). Um estudo econométrico sobre as variáveis macroeconômicas e sua relação com o Ibovespa no período julho de 1996 até Dezembro de 2013. XIII Simpósio de Excelência em Gestão e Tecnologia - SEGeT. https://www.aedb.br/seget/arquivos/artigos16/10724159.pdf.

Moura, R (2018). A cronologia da crise do diesel, do controle de preços de Dilma à greve dos caminhoneiros. BBC News. https://www.bbc.com/portuguese/brasil-44239437.

Nunes Maranhão, A. \& de Oliveira, W. S. M. (2017). Spillovers de volatilidades cambiais e efeito lead-lag no mercado acionário brasileiro. Revista Brasileira de Economia de Empresas/Brazilian Journal of Business Economics, 17(2).

Nunes, R. V. \& Sales, G. A. W. (2017). Uma Análise Comparativa Baseada em Indicadores entre a Petrobras e as Concorrentes Estrangeiras-Do Anúncio do Pré-Sal até os dias atuais. Revista Eletrônica do Departamento de Ciências Contábeis \& Departamento de Atuária e Métodos Quantitativos (REDECA), 4(2), 61-78.

Padula, A. J. A. \& Albuquerque, P. H. M. (2018). Corrupção governamental no mercado de capitais: um estudo acerca da Operação Lava Jato. Revista de Administração de Empresas, 58(4), 405-417.

Petrobras (2016). Adotamos nova política de preços de diesel e gasolina. Fatos e dados. http://www.petrobras.com.br/fatos-e-dados/adotamos-nova-politicade-precos-de-diesel-e-gasolina.htm.

Petrobras (2021). Quem somos, Trajetória. http://www.petrobras.com.br/pt/quem-somos/trajetoria/.

Sant'anna, A. M (2008). Principais Fatores que Influenciam no Preço de Ações das Empresas de Papel e Celulose na BM\&FBovespa. Trabalho de Conclusão de Estágio Desenvolvido para o Estágio Supervisionado do Curso de Administração do Centro de Ciências Sociais Aplicadas da Universidade do Vale do Itajaí. http://siaibib01.univali.br/pdf/Andre\%20Machado\%20Santanna.pdf.

Santos, D. B; et al (2015). Influência Intradiária do Preço Internacional do Petróleo nas Ações da Petrobrás. Journal of Financial Innovation, 1.pp. 4-17. https://papers.ssrn.com/sol3/papers.cfm?abstract_id=2532923.

Shimabuku, F. A. A. (2017). Causas e consequências da operação lava-jato: um estudo econômico e socioambiental da Petrobrás. Dissertação de Mestrado em Controladoria Empresarial. Universidade Presbiteriana Mackenzie.

Silva, A. M. et al (2005). Um Estudo da Relação Entre os Fatores Externos e o Valor das Ações. Caso das Empresas de Energia Elétrica do Brasil. II Simpósio de Excelência em Gestão e Tecnologia - SEGeT'2005. https://www.aedb.br/seget/arquivos/artigos05/15_Energia\%20Eletrica\%20do\%20Brasil.pdf. 
Research, Society and Development, v. 10, n. 7, e13410716294, 2021

(CC BY 4.0) | ISSN 2525-3409 | DOI: http://dx.doi.org/10.33448/rsd-v10i7.16294

Silva, B. F. D (2010). Relações entre o Preço Internacional do Petróleo e as Ações da Petrobrás. Dissertação (mestrado) - Universidade Federal de Brasília, Universidade Federal da Paraíba e Universidade Federal do Rio Grande do Norte, Programa Multiinstitucional e Inter-Regional de Pós-Graduação em Ciências Contábeis. http://repositorio.unb.br/bitstream/10482/8848/1/2011BrunoFernandesDiasdaSilva.pdf.

Sims, C. A. (1980). Macroeconomics and reality. Econometrica: journal of the Econometric Society, 1-48.

Sims, C. A., Stock, J. H., \& Watson, M. W. (1990). Inference in linear time series models with some unit roots. Econometrica: Journal of the Econometric Society, 113-144.

Viegas, T. O. C., De Paula, G. M (2018). A relação imbricada entre custos de extração e preços do petróleo cru. Petro \& Química, 1(28). 